\title{
RETURNS TO LOCAL-AREA HEALTH CARE SPENDING: USING HEALTH SHOCKS TO PATIENTS FAR FROM HOME
}

\author{
Joseph J. Doyle, Jr. \\ Working Paper 13301 \\ http://www.nber.org/papers/w13301 \\ NATIONAL BUREAU OF ECONOMIC RESEARCH \\ 1050 Massachusetts Avenue \\ Cambridge, MA 02138 \\ August 2007
}

I would like to thank Amy Finkelstein, Jon Gruber, Robert Kaestner, Lorens Helmchen, Roberto Rigobon, Doug Staiger, Tom Stoker, and Tavneet Suri for helpful comments and discussions. Afua Branoah Banful provided excellent research assistance. The views expressed herein are those of the author(s) and do not necessarily reflect the views of the National Bureau of Economic Research.

(C) 2007 by Joseph J. Doyle, Jr.. All rights reserved. Short sections of text, not to exceed two paragraphs, may be quoted without explicit permission provided that full credit, including $\odot$ notice, is given to the source. 
Returns to Local-Area Health Care Spending: Using Health Shocks to Patients Far From Home Joseph J. Doyle, Jr.

NBER Working Paper No. 13301

August 2007

JEL No. I12

\begin{abstract}
$\underline{\text { ABSTRACT }}$
Health care spending varies widely across markets, yet there is little evidence that higher spending translates into better health outcomes, possibly due to endogeneity bias. The main innovation in this paper compares outcomes of patients who are exposed to different health care systems that were not designed for them: patients who are far from home when a health emergency strikes. The universe of emergencies in Florida from 1996-2003 is considered, and visitors who become ill in high-spending areas have significantly lower mortality rates compared to similar visitors in lower-spending areas. The results are robust across different types of patients and within groups of destinations that appear to be close demand substitutes.
\end{abstract}

Joseph J. Doyle, Jr.

MIT Sloan School of Management

50 Memorial Drive

E52-447

Cambridge, MA 02142

and NBER

jjdoyle@mit.edu 


\section{Introduction}

Health care spending is a major issue in the U.S., amounting to over \$2 trillion per year or 16\% of GDP (Catlin et al., 2007). These figures are expected to increase with the aging of the population and are likely to strain government budgets and private-sector profitability (Lee and Skinner, 1999).

There is some controversy over the returns to health care spending. When countries or regions within the U.S. are compared, large disparities in spending are found yet health outcomes are remarkably similar (Fisher et al., 1994; Pilote, et al., 1995;

Kessler and McClellan 1996; Tu et al., 1997; O’Connor et al., 1999; Baicker and Chandra 2004; Fuchs 2004; Stukel, Lucas, and Wennberg, 2005; Sirovich, et al., 2006). Fisher et al. (2003) studied Medicare expenditure data and found that end-of-life spending levelsa measure of treatment intensity that controls for the health outcome-are $60 \%$ higher in high-spending areas compared to low-spending ones in the U.S. Nevertheless, no difference is found across regions in 5-year mortality rates following a health event such as a heart attack or hip fracture. Related studies have suggested that higher spending is associated with worse health outcomes (Guadagnoli et al., 1995; Fisher and Welch, 1999), and this evidence has been cited in support of limits on Medicare growth. Alternatively, time-series and panel data evidence of higher spending and lower mortality have suggested that the value of life years saved by increased health care spending has been greater than the extra expense (Cutler, McClellan, Newhouse, and Remler, 1998, McClellan and Newhouse 1997; Murphy and Topel, 2003; Cutler and McClellan, 2001; Nordhaus 2002; Cutler, Rosen and Vijan, 2006; Luce et al., 2006). 
One issue that arises when comparing regions is that greater treatment levels may be chosen for populations in worse health. For example, higher spending is strongly associated with higher mortality rates on the individual level, as more is spent on patients with greater health problems. At the regional level, long-term investments in capital and labor may reflect the underlying health of the population as well.

The main innovation in this paper compares outcomes of patients who are exposed to different health care systems that were not designed for them: patients who are far from home when a health emergency strikes. These visitors may have a health emergency in an area that spends a great deal on patients or one that tends to spend less. By comparing similar visitors across these locations, differences in health outcomes can shed light on the returns to health care spending, at least in emergency situations. ${ }^{1}$

The analysis uses the universe of hospital discharges in the state of Florida—one of the most frequently visited states, which also has a wealth of data regarding patient characteristics. Patients who have a health emergency in a high-spending area are found to receive more care themselves and have significantly lower inpatient mortality rates. A typical comparison of a high-spending area and a low-spending one would represent a $50 \%$ difference in health care spending intensity. Such a disparity is associated with a 1.6 percentage-point lower mortality rate among heart emergency patients compared to a mortality rate of $6 \%$.

\footnotetext{
${ }^{1}$ Previous papers considered patients who used the nearest health care system to their homes (McClellan, McNeil, and Newhouse 1994; Gowrisankaran \& Town 1999; Stukel et al., 2007). This paper also considers patients who use the nearest health care system, although the starting point is more likely to be exogenous as the patients are far from home at the time of the episode and visitors may choose a destination for a number of reasons other than the health care-spending level in the area. Similarly, the health care market is considered rather than individual hospitals, as the market is also more likely to be exogenous than the particular hospital chosen by a patient or emergency medical services.
} 
Of course, visitors choose their destinations, and if relatively healthy individuals were to choose high-spending areas, the main results would reflect these differences. Much of the results section demonstrates that the estimates are robust across different types of patients, including patient-income levels, and within groups of destinations that can be characterized as close demand substitutes. In addition, the results suggest that destination selection would tend to bias the results away from finding a negative relationship between spending and mortality.

The outline of the paper is as follows. Section 2 presents the empirical framework. Section 3 describes the data, including a comparison of high- and lowspending counties in terms of patient characteristics. Section 4 presents the main estimates of the relationship between inpatient mortality and local-area health care spending. The analysis focuses on heart conditions, though results for other common emergencies are reported as well. Section 5 interprets the results by considering how local areas that spend more differ from those that spend less and presents instrumental variable estimates of the effect of patient spending on health outcomes in these emergency situations. Section 6 concludes.

\section{Empirical Framework}

Consider a simple health production function:

(1) $\mathrm{M}=\mathrm{M}(\mathrm{T}, \mathrm{X}, \mathrm{U})$

$$
\frac{\partial \mathrm{M}}{\partial \mathrm{T}} \leq 0 ; \frac{\partial^{2} \mathrm{M}}{\partial \mathrm{T}^{2}}>0 ; \frac{\partial \mathrm{M}}{\partial \mathrm{X}}>0 ; \frac{\partial \mathrm{M}}{\partial \mathrm{U}}>0 ; \frac{\partial^{2} \mathrm{M}}{\partial \mathrm{T} \partial \mathrm{X}}<0 ; \frac{\partial \mathrm{M}}{\partial \mathrm{T} \partial \mathrm{U}}<0
$$

where $\mathrm{M}$ is a health outcome (mortality), $\mathrm{T}$ is the level of treatment, $\mathrm{X}$ represents observable (to the researcher) measures of illness severity and $\mathrm{U}$ represents severity 
measures unknown to the researcher. Treatment is assumed to reduce the likelihood of mortality with diminishing returns, and the benefits are assumed to increase with illness severity. This production function can be defined at the patient or regional level.

The parameter of interest is the effect of treatment on health. For instance, if spending in an area can be categorized as high or low, the parameter would be as follows:

(2) $\mathrm{E}\left(\mathrm{M} \mid \mathrm{T}_{\text {high }}, \mathrm{X}, \mathrm{U}\right)-\mathrm{E}\left(\mathrm{M} \mid \mathrm{T}_{\text {low }}, \mathrm{X}, \mathrm{U}\right)$

This is an estimate of the benefits to health care spending, and for small changes in treatment levels it can be interpreted as the slope of the production function. In a linear model, this can be summarized as:

(3) $\mathrm{M}=\beta_{0}+\beta_{1} \mathrm{~T}+\beta_{2} \mathrm{X}+\mathrm{U}$

The parameter of interest is $\beta_{1}$, but the inference problem is that treatment levels likely vary with illness severity $-\operatorname{Cov}(\mathrm{T}, \mathrm{U})>0$ - which will bias estimates of this parameter upwards. Previous studies have argued that observable patient characteristics are similar across areas (see, for example, O’Connor et al., 1999; Pilote et al., 1995; Stukel, Lucas, and Wennberg, 2005; and Fisher et al., 2003). Fisher et al. (2003) found higher predicted mortality rates in higher-spending areas for heart attack patients, however, and differences in unobservable characteristics may lead to an upward bias as well.

The source of the endogeneity bias can be described by the decisions made by health care providers. Following McGuire and Ellis (1986), assume they maximize a utility function that is additively separable between profits and health benefits for each patient:

(4) $\max _{\mathrm{T}} U(\mathrm{~T})=\Pi(\mathrm{T})+\lambda \mathrm{M}(\mathrm{T}, \mathrm{X}, \mathrm{U})$ 
where lambda is the weight placed on health impacts of the treatment decision. Here, lambda is negative given that $\mathrm{M}$ is a measure of mortality. The maximization problem is constrained by:

(5) $\mathrm{T} \leq \mathrm{F}(\mathrm{K}, \mathrm{L}) \quad$ and

(6) $\mathrm{T} \leq \mathrm{R}(\mathrm{X}, \mathrm{U})$

Constraint (5) is a technological one relating the available treatment to the capital, $\mathrm{K}$, and labor, L, previously chosen by the area. This constraint has been highlighted as a source of variation in treatment across markets, as regions with greater assets tend to provide more treatment across all patients (Fisher et al., 1994; Stukel, Lucas and Wennberg, 2005).

Meanwhile, (6) is a resource constraint where $\mathrm{R}$ represents expenses that are approved for reimbursement by third-party payers. It is a function of the severity of illness, as third-party payers reimburse hospitals for greater expenses when patients are in worse health. It is also a function of the generosity of the patient's health insurance, which can vary with patient characteristics such as household income.

At the regional level, capital and labor are not fixed in the long run. Rather, these inputs may be chosen to maximize a population version of (4)-(6). In areas where the population is in worse health, greater treatment levels will be covered by third-parties and providers would have the incentive to invest in greater resources.

Now consider areas that differ in the health of their populations. This simple model highlights three reasons why treatment and illness severity should be positively related: larger benefits to patient health due to the complementarity between illness severity and treatment; the greater ability to spend through less stringent constraints in the short run; and greater investments in physical and human capital due to the prospects 
of greater reimbursement levels in the long run. Each implies that $\operatorname{Cov}(T, U)>0$ at the regional level. Alternatively, marginal costs that enter the profit function may be increasing in severity as well, though such an influence may be offset by the third-party payment mechanism highlighted in constraint (6).

To summarize, Figure 1 shows hypothetical mortality-treatment relationships for two populations that differ by their underlying health. The figure has been drawn such that the mortality rates across the groups are the same. If this cross-sectional relationship between treatment levels and mortality rates were thought to stem from one production function, it would appear that we have reached the "flat of the curve" (Enthoven, 1980; Fuchs, 2004). If these data represent points on different production functions, as in Figure 1, the returns to health care spending need not be zero.

This paper attempts to circumvent this endogeneity bias by considering a population served by different hospital markets where the spending levels are unlikely to be affected by the presence of this group: patients far from home at the time of a health shock. For visitor i treated in county c, the linear model can be written as:

(7) $\mathrm{M}_{\mathrm{ic}}=\beta_{0}+\beta_{1} \mathrm{~T}_{\mathrm{c}}+\beta_{2} \mathrm{X}_{\mathrm{i}}+\mathrm{U}_{\mathrm{ic}}$ where the identifying assumption is: $\operatorname{Cov}\left(\mathrm{T}_{\mathrm{c}}, \mathrm{U}_{\mathrm{ic}}\right)=0$.

One threat to identification is that visitors choose their destination. If they base their decision on the health care-spending levels in the different areas, visitors in relatively worse health may choose areas with high-treatment levels. This selection would tend to bias the results toward finding a positive correlation between spending and mortality. Alternatively, if healthier individuals chose high-spending areas, then the bias would go the other direction. For example, if wealthier individuals were both healthier 
and chose destinations that were expensive along many dimensions, one of which happens to be health care spending, then a high level of health care spending in an area may be an indicator for a healthier visitor population. The empirical analysis will consider patients with similar observable characteristics, including income levels, as well as results within groups of destinations that appear to be close demand substitutes where observable and unobservable characteristics of patients are more likely to be similar across health care markets.

\section{Data Description}

The patient-level data represent the universe of hospital discharges in the state of Florida from 1996 to 2003. These reports are submitted to the Florida Agency for Health care Administration and are available for research purposes. The two main advantages of using Florida are that it is a top destination state leading to large samples of visitors, and the state offers detailed discharge data. Elements include the patient's age, race, sex, and ZIP code of residence. Procedure and diagnosis codes, primary payer, day of the week, and quarter of the year also describe the episode.

In the main analysis, a visitor is defined as an out-of-state patient, and hospital markets are defined at the county level. The sample is restricted to counties with at least 30 such visitors with a heart emergency. This results in 44 (out of 67) Florida counties with enough visitors to compare patient outcomes. Further, the analysis will use withinhome state variation in treatment and outcomes, and the sample has been limited to visitors from U.S. states with at least 5 observations or from outside the U.S. 
The main measure of resource use is total charges: the sum of the list prices for each of the services provided. Few patients (or third parties) pay these list prices. Rather, insurance companies negotiate discounts from these starting values. Nevertheless, total charges are highly correlated with cost measures and serve to categorize high- versus low-spending areas. Other measures of facility costs will be explored as well.

Following Fisher et al. (2003), end-of-life spending among the local population is used to measure local-area spending intensity. This measure has the advantage of controlling for patient health outcomes when describing treatment intensity. In particular, the mean of log charges in the county was calculated for patients from Florida who were admitted on an emergency basis and who died in the hospital. ${ }^{2}$ Algebraically, this is the county fixed effect in a model predicting log charges for this sample of locals.

Alternative measures of treatment intensity are also compared.

The health outcome considered is inpatient mortality. One limitation of these data is that they do not include longer-term outcomes, though for serious health emergencies inpatient mortality is a frequent and important one. In addition, for the visitor group inpatient mortality is tied more directly to the acute care provided by Florida health care system, whereas long-term outcomes may be influenced by the care received once home. Further, an advantage of the discharge data compared to previous studies that use Medicare administrative data is that younger patients can be considered, as well as patients enrolled in Medicare HMOs who are generally lost from Medicare expenditure files.

\footnotetext{
${ }^{2}$ Emergencies in this paper are defined by the admission type (emergency) and admission source (emergency room). This limit should exclude patients who travel to a particular destination for the purpose of hospital treatment.
} 
U.S. Census of Population data from 2000 describe the patient's ZIP code of residence, including the median household income, racial composition, educational composition among individuals older than 25-years old, and the population. One issue is that $15 \%$ of the visitors are not from the U.S. and will not have a ZIP code. In addition, the Census Bureau does not publish data for small ZIP codes. In total, ZIP code information is missing for $25 \%$ of the visitor sample. The main results will retain these observations by filling in the missing information with sample means and including an indicator for missing ZIP code information in the model. Results are similar when these observations are excluded, as shown below. Similar U.S. Census measures for the destination county in Florida are considered as well.

In addition, results will be shown controlling for prices related to visiting that particular county. These prices come in the form of per-diem rates calculated by the U.S. General Services Administration (GSA). The per-diems are based on lodging and meal rates in each county and should characterize destinations with similar prices that are especially appropriate for visitors. Given the seasonal variation in these rates, two measures will be used: the per diem for January 1997 and the per diem for June 1997. ${ }^{3}$ Each measure should reflect local-area cost structures, and the difference in the two measures should identify areas that are particularly desirable for winter vacations. One caveat is that these measures may over-control for variation in spending levels if estimates of the returns to total expenditures (price times quantity) were sought. From a fiscal perspective, total expenditures would appear more appropriate, though controlling for the local-area prices attempts to control for differences in visitors who visit more or

\footnotetext{
${ }^{3} 1997$ is the first year this lodging-rate data are available. Results were similar when 1996 data were imputed and the series from 1996-2003 was used instead of the fixed 1997 measure as described below.
} 
less expensive areas and can shed light on returns to the quantity of care provided. Results will be reported with and without these controls.

Further, the 1995 American Travel Survey describes visitors to each of 13 destinations, spanning 24 counties in Florida. These data will be used in a specification check that controls for these characteristics on this subset of counties. Last, American Hospital Association data detailing information about each hospital in Florida will be used to describe the different areas in terms of staffing ratios and wage bills.

To describe the data available and compare visitors across different areas in Florida, Table 1 reports means for selected characteristics of patients who had a heart emergency. Heart emergencies are defined for patients who are admitted with a primary diagnosis of acute myocardial infarction (AMI), cardiac dysrhythmias, or heart failure. ${ }^{4}$ They have the advantage of potentially being unanticipated at the time of the destination choice. ${ }^{5}$ One caveat is that heart emergencies are amenable to highly efficient, low-cost innovations, such as the use of beta blockers and aspirin (Heidenreich and McClellan, 2001), though the analysis here focuses on spending in the health care market overall.

The first two columns report means and standard deviations for the 750,000 Floridians with a heart emergency admission during this time period to serve as a comparison for the visitors. The means for the visitors have been broken into two groups based on the median level of the local-area treatment measure to compare high- and lowspending areas. The advantage of Florida having many visitors is demonstrated by the

\footnotetext{
${ }^{4}$ These are 3-digit ICD9-CM primary diagnosis codes of 410, 427, and 428. They are the heart emergencies among the top 10 most frequent emergencies. Results broken out for each of the top 10 most frequently found emergencies are discussed below.

${ }^{5}$ Only $0.16 \%$ of the AMIs among visitors were the results of a "subsequent episode of care" versus $0.4 \%$ among locals.
} 
18,000 visitor emergencies in each of the spending categories, or $5 \%$ of the heart emergencies in Florida overall.

For patients from Florida, the local-area spending intensity measure (mean, endof-life log charges) averages 10.0 , or $\$ 22,000$. By construction, low-spending areas have an average spending measure $37 \log$ points lower than the mean for visitors in highspending areas. Areas that tend to spend more on local patients also report higher spending on visitors themselves: a difference of 24 log points.

Visitors who have a health emergency in a high-spending area have a lower mortality rate: $5.4 \%$ vs. $6.1 \%$. These figures are similar in magnitude to the mortality rate among locals (5.7\%), suggesting that results for the visitor group may be informative of returns to spending for the local group as well.

One threat to the identification is that individuals who visit high-spending areas may differ from those who visit low-spending ones. The observable characteristics describe the types of visitors who are found in different areas. In particular, the high- and low-spending areas are similar in terms of sex, though visitors with heart emergencies are more likely to be male compared to locals (62-63\% vs. 52\%). Visitors to high-spending areas are 2.8 years younger than low-spending areas, whose average age of 71.6 is similar to the local population. The empirical models will include controls for each year of age, and results will be compared within age groups as well. Similarly, the visitors in lowspending areas are more likely to receive Medicare, partly due to the age difference and partly due to the presence of patients from foreign countries in the high-spending group, which includes Miami-Dade County. 
Meanwhile, visitors in high-spending areas are more likely to be from ZIP codes with slightly lower median household incomes and college graduation rates. Treatment differences have been found to vary by race as well, with White patients typically receiving more care (Institute of Medicine, 2002), though visitors to high-spending areas are more likely to be non-White.

Further, the per-diem rates for July are slightly higher for the high-spending area (\$102 vs. \$97), though this is not found for the per-diem in January (\$107 vs. \$113). Fortunately, health care spending varies widely even within destinations with similar lodging and meal prices. When counties were broken into quartiles based on the January per-diem rate, the average, end-of-life log charges from the least to most expensive are $9.9,9.9,10.2$, and 9.9 , with standard deviations of $0.24,0.23,0.14$, and 0.11 , respectively.

The timing of the emergency is also recorded, albeit at the quarter-of-year and day-of-week levels. For Florida locals, the entry rate is roughly uniformly distributed across quarters, with slightly higher rates during the first and fourth quarters, possibly reflecting visitors who maintain a residence in the relatively tax-friendly state of Florida. For visitors, the first quarter was the most common time of the year (50\% in lowspending areas and $44 \%$ in the high-spending ones), with fewer during the 3rd quarter (11\% in low-spending areas and $13 \%$ in high-spending areas). Meanwhile, an admission on Saturday or Sunday is only slightly higher for the visitor group, and they are all close to the 2/7th rate expected for emergencies (Dobkin, 2003).

To summarize the differences across the two groups, a predicted-mortality measure was estimated using a probit model and the full set of controls, including individual indicators for each age and day of the week. Age, insurance type, and quarter 
of the year appear related to mortality. Nevertheless, the predicted mortality rates are nearly identical across the two groups, implying that they are comparable in terms of observable characteristics that are correlated with mortality.

For further context, the local-area patients in the two groups of counties can be compared. The differences reflect those found among the visitors, although the magnitudes tend to be larger. For example, patients from Florida receiving care in lowspending counties are much more likely to be White (87\%) compared to high-spending areas (67\%). Among high-spending counties, the fraction African American and Hispanic are $12.8 \%$ and $17.5 \%$, respectively, compared to $9.2 \%$ and $2.1 \%$ in lowspending areas. The other major difference across the observables is the primary payer. Those in low-spending counties are more likely to receive Medicare fee-for-service benefits (66\% vs. 49\%) and are less likely to join a Medicare HMO (8\% vs. 18\%). Other differences for those in low-spending counties include ZIP codes with a slightly higher education level (19\% with less than a high school degree vs. 23\%), and a slightly higher average age (72.4 vs. 71.3). The predicted mortality rate based on all of the observable characteristics is similar across the two sets of counties (5.66\% vs. 5.70\%), although relatively large differences in observable characteristics suggest that unobservables may differ across the two groups.

\section{Results}

Following the framework in section 2, the empirical models will consider the outcome of inpatient mortality, M, for patient i hospitalized in county c, from ZIP code z in state s, in year t as: 
(8) $M_{\text {iczst }}=\alpha_{0}+\alpha_{1} T_{c}+\alpha_{2} X_{i}+\alpha_{3} W_{z}+\alpha_{4} P_{c}+\theta_{s}+\delta_{t}+v_{\text {iczst }}$

where $\mathrm{T}$ is the measure of local-area spending: mean log charges for emergency patients from Florida who died in the hospital in the county visited by patient $\mathrm{i}$; $\mathrm{X}$ is a vector of personal characteristics listed in Table 1 with indicators for each age and day of the week as well ${ }^{6}$; W is a set of ZIP code of residence characteristics including 7 indicators for median household income ( $<\$ 30,000$ and $\$ 10,000$ increments up to the $>\$ 80,000$ category), 2 racial-composition variables (fraction White and African American), 3 educational-composition variables (fraction of individuals 25 years and older with less than high school, high school, and some college educational attainment), and ZIP code population; and $\mathrm{P}$ is the vector of area per-diem rates in January and June 1997. Homestate fixed effects are used to compare individuals from the same state who visit different counties in Florida, and year indicators are used to capture overall changes in survival rates over time. ${ }^{7}$ The outcome is binary, and the results are shown using a linear probability model to estimate differences in means across counties. Results are similar when a probit model is used as shown below. Also, the standard errors are clustered at the county level to reflect variation in the local-area spending measure.

Table 2 shows the main results for the universe of patients who entered the hospital with a heart emergency. The top panel considers the local Florida population, as in the previous literature. The first four columns report estimates from a model similar to (8), but with charges spent on that particular patient, $T_{i}$, in place of the local-area treatment measure. Regardless of the controls used, the estimates reveal that a $10 \%$

\footnotetext{
${ }^{6}$ Individual age categories are used, with the exception of larger categories for patients under the age of 20 , between 20 and 30, and above 100 years old.

${ }^{7}$ In addition to indicators for each U.S. state, indicators for Canada, the Americas, and unknown state of residence, which is used to describe foreign visitors, are included as well. Estimates are similar when patients from outside the U.S. are excluded, as shown below.
} 
increase in spending is associated with a 0.27 percentage-point increase in mortality, or $5 \%$ of the mean mortality rate of $5.7 \%$. These results are consistent with the idea that more is spent on patients who are in worse health.

When the mean end-of-life spending measure for the county, $\mathrm{T}_{\mathrm{c}}$, is used instead of the patients own spending, mortality appears unrelated to the spending level in the county. The coefficient on county spending ranges from 0.001 to 0.005 with standard errors on the order of 0.004 . These results mirror the prior literature that higher spending is associated with a small, statistically insignificant, increase in mortality.

Panel B shows the results for patients who are not from Florida, using the same models as in panel A. The results are nearly identical when the patient's own charges are used to predict mortality, with a coefficient of 0.028 . When the end-of-life spending measure for the local-area population is used, however, the sign flips and the coefficient is closer to -0.030 . A $10 \%$ increase in "spending intensity" is associated with a 0.3 percentage-point decrease in mortality, or $5 \%$ of the mean. For a two-standard deviation increase in spending of roughly $50 \%$, mortality rates would be 1.5 percentage points lower, or $26 \%$ lower than the mean. The results are robust to the inclusion of controls for patient and area characteristics, including the income level of the ZIP code where the patient resides. The results suggest that having a heart emergency in an area that tends to spend more on patients is associated with significantly lower mortality.

In terms of the relationship between patient characteristics and mortality (shown in the appendix), older patients have higher mortality rates, with 85 year olds having a 6 percentage-point higher mortality rate than 60 year olds. Visitors in the 1st quarter-the most likely time to escape cold winters-have a 1.1 percentage-point lower mortality rate 
compared to 4th-quarter visitors, whereas those who visit in the 2nd and 3rd quarters have slightly higher mortality rates compared to the 4 th-quarter visitors. The uninsured have a 1 to 2 percentage-point higher mortality rate compared to the different types of insured patients. Those in Medicare HMOs have a 1 percentage-point lower mortality rate compared to those in fee-for-service Medicare, possibly reflecting the attraction of healthier individuals to these plans (Cao and McGuire, 2003). From the ZIP code characteristics, the most striking result is that individuals from high-income, higheducation areas tend to have lower survival rates. The mortality rate for patients from ZIP codes with median household income greater than 80,000 is 1.6 percentage points higher than for patients from ZIP codes with incomes less than 30,000. Last, the perdiem rate in January is negatively related to mortality, whereas the per-diem rate in July is positively related to mortality, though the coefficients are fairly small in terms of economic significance. ${ }^{8}$

To test the shape of the relationship between local-area charges and mortality, the counties were broken into quartiles based on the end-of-life spending measure. This is a fairly coarse categorization, as is required by having 44 counties to analyze. It does provide some confidence that the top quartile likely represents a different degree of spending compared to the bottom quartile. In particular, for the top 3 quartiles, the spending measure increases by 22, 40, and $65 \log$ points compared to the bottom quartile. Meanwhile, the reduction in mortality is fairly smooth across the quartiles with differences compared to the 1 st quartile of -0.005 (s.e. $=0.006$ ), -0.010 (s.e=0.006), and -

\footnotetext{
${ }^{8}$ When 1996 per-diem data were imputed using a time trend though the 1997-2003 GSA data and the model incorporated this time series rather than the 1997 values, the results were similar with coefficient on local-area spending of -0.027 (s.e. $=0.008$ ).
} 
0.019 (s.e. $=0.006$ ). ${ }^{9}$ The larger drop in the top quartile is consistent with higher returns in more intensive areas, as suggested by models with productivity spillovers (Chandra and Staiger, 2007).

\section{Results across Diagnoses}

Table 3 reports results for a wider range of diagnoses. This allows an exploration of the types of conditions that may or may not benefit from hospitalizations in highspending areas compared to low-spending ones.

First, the top-10 most frequent emergency diagnoses in Florida over this time period are considered. The above results pooled primary diagnoses of acute myocardial infarction (heart attacks), cardiac dysrhythmias, and heart failure. Table 3 disaggregates the data and shows that the lower mortality rates are found for each of the conditions. Stroke patients also have a significantly lower mortality rate when served by a highspending area, with a coefficient of -0.043 compared to a mortality rate of $6.3 \%$.

The other conditions have negative coefficients but are not statistically significant. In particular, two conditions with reasonably large mortality rates but relatively smaller coefficients are pneumonia and chronic bronchitis. To the extent that these patients are more likely to include long-term visitors (otherwise, the visitor would be less likely to make the trip), we would expect the results to more closely reflect the lack of a relationship found among locals in panel A of Table 2. If this were true for the heart conditions, the relationship in the main results would be biased against finding the negative relationship.

\footnotetext{
${ }^{9}$ These results are in the appendix. When these quartiles were not equally weighted across counties but used the number of patients as weights instead, the second and third quartiles have a 1 percentage point drop in mortality and a larger decline is found in the top quartile - a 2.5 percentage-point lower mortality rate compared to the bottom quartile.
} 
In addition, all emergencies were considered in a model similar to equation (8) with three-digit diagnosis fixed effects included as well. The coefficient on end-of-life spending in the county is -0.017 (s.e. $=0.005$ ). A $10 \%$ increase in spending is associated with a $4.4 \%$ reduction in mortality compared to the mean mortality rate of $3.9 \%$--a result similar to the heart emergency result found in Table 2.

One issue when considering all diagnoses is that there are some hospitalizations where the risk of death is essentially zero for all patients, and inpatient mortality is simply not an informative outcome to study. To consider diagnoses with different mortality rates, a probit model of mortality was estimated using 3-digit diagnosis codes among diagnoses with at least 10 observations and 1 death. The predicted mortality rate was then broken into quartiles, and a model similar to (8) was estimated within each of the quartiles. Three-digit diagnosis fixed effects were again included. Table 3 shows that the coefficients are negative in all four categories, though statistical (and economic) significance is achieved for diagnoses with higher mortality rates. In the top quartile, the mortality rate is $12 \%$, and among the 62,000 visitors with a primary diagnosis in this quartile, a $10 \%$ increase in local-area spending is associated with a 0.43 percentage-point decrease in mortality (or 3.6\% of the mean). The comparable figure for the third quartile is $5.7 \%$ of the mean. It appears that the reduction in mortality is present across a wide range of emergency situations.

\section{Dehydration}

One specification check considers a condition where relatively low-cost treatment is fairly uniform across areas. If mortality for such a condition were related to local-area 
spending, it would appear that factors other than the type of health care provided may drive the mortality differences, such as the underlying health of the visiting population.

A condition that appears to be the best candidate is dehydration. Among primary diagnoses with a mortality rate of greater than $1 \%$ and at least 300 observations , average patient charges were the lowest for dehydration. This suggests that treatment for dehydration should be available to hospitals regardless of their technological capabilities.

Further, the treatment appears to be fairly uniform across Florida. Consider a model of log charges on local-area, end-of-life charges and full controls. Among 3-digit primary diagnoses with at least 1500 visitor observations, dehydration is the diagnosis with the smallest coefficient on the local-area spending measure (albeit not zero, with a coefficient of 0.41 and a standard error of 0.10 ). In contrast, heart emergencies have a coefficient of 0.7 .

Patients with this primary diagnosis have a mortality rate of $2.2 \%$, and in the mortality model (8) the coefficient on the local-area spending measure is close to zero (coefficient $=-0.003$, s.e. $=0.015, \mathrm{n}=3318$ ). If healthier individuals tended to visit highspending areas to account for the main results, a lower mortality rate among those with this condition would be expected as well. Rather, this test is consistent with similar underlying health status across destinations, albeit for a particular diagnosis.

\section{Patient Characteristics}

Table 1 shows that high-spending areas differed somewhat from other counties, and a comparison of the results within similar patient groups serves to control for each characteristic. Further, returns to spending may differ by group. Table 4 reports 
estimates for heart emergency patients within sub-samples defined by patient characteristics.

The first set of comparisons is for patients who are over or under the age of 65 . The over-65 group is mostly covered by Medicare (with the exception of foreign visitors, mostly likely to be found in Miami) and is more likely to include "snow birds" who winter in Florida. The results show a negative relationship between local-area spending and mortality: a coefficient of -0.037 compared to a mean mortality rate of $6.8 \%$. For those under the age of 65 the relationship is similar compared to a lower mortality rate of $3.2 \%$ with a coefficient of -0.017 .

The next comparisons are in terms of race and sex. The bulk of the visitor sample is White, and the coefficient is similar to the main results for this group (-0.030). For the smaller sample of African Americans $(n=1,484)$, higher spending is associated with a larger reduction in mortality: a coefficient of -0.067 compared to a smaller mean mortality rate of 0.047 . Hispanic patients $(n=1,545)$ had a similarly large estimated return with a coefficient of -0.052 compared to a mean mortality rate of 0.051 . Returns to spending appear to be higher for women (with a coefficient of -0.049 vs. -0.022 ) compared to a higher mean mortality rate (6.4\% vs. $5.4 \%)$.

The time of year can distinguish between different types of trips—vacations in the winter and business trips and less-expensive vacations in the summer. Again, the negative relationship is found for each group, with a larger magnitude in the third quarter (July, August, \& September). The largest group of visitors is found in the cold months of January, February, and March $(n=17,191)$, and the coefficient on local-area spending is -0.026 compared to a mean mortality rate of $5 \%$. 
In terms of insurance status, the returns to high-spending areas are somewhat larger for the insured compared to the uninsured (-0.033 vs. -0.024). In a separate analysis of these emergencies, the uninsured are found to receive less treatment than the insured and have higher mortality rates (controlling for patient characteristics and hospital fixed effects). It appears that higher-spending areas may offer more benefits to the insured because they tend to consume a greater amount of care once in the hospital.

Patients who come from different parts of the country may have different underlying risks of inpatient mortality. The main results used a model that included home-state fixed effects, and columns (13)-(16) show qualitatively similar results regardless of the census region of origin. The northeast appears to have the greatest reduction in mortality with increased spending (coefficient of -0.045), whereas the Midwest has the smallest gain (coefficient of -0.021).

The last set of patient characteristics considers the median household income of the patient's ZIP code of residence. Higher health care spending may signal higher incomes among the visitors, though that was not found in the means comparison in Table 1. In addition, the covariates in the main results suggested that income was positively related to mortality for these emergencies. The main results controlled for 7 income categories, and Table 4 reports the results by income quartile for patients who have ZIP code information. The relationship between the returns to local-area spending and income is not monotonic, with the largest returns found for the bottom and top quartiles. Nevertheless, the results are qualitatively similar when estimated within each of these groups. Last, when observations are excluded when they have missing ZIP code 
information, which includes foreign visitors, the result is similar to the main results (coefficient of -0.033).

\section{Florida County Characteristics}

As in the comparisons across patient types, counties that differ by local-area health care spending may differ along a number of other grounds. These differences may attract different types of visitors and different types of hospital staff. To test whether these county differences drive the main results, Table 5 reports some specification checks. $^{10}$

The first set of models considers the per-diem rates used as controls in the main results. If destinations were close substitutes, we would expect similar lodging and meal prices. Further, if hospital-spending levels did not enter the decision to choose a destination, then visitors to areas that are close substitutes would likely be similar as well. In that spirit, Table 5 reports the results for sub-samples defined by quartiles of the perdiem rates in an effort to compare destinations with similar prices. The bottom quartile represents the 17 counties where the per-diem rate is the state-level rate of $\$ 80$. These counties tend to be visited less frequently. The next three quartiles have per-diem rates that range from $\$ 81-99, \$ 100-116$, and $\$ 117-214$, respectively. The $\$ 214$ per-diem rate is for Monroe County, which includes the Florida Keys; the next most expensive county has a per-diem rate of $\$ 132$. The bulk of the data reside in the top quartile, which also includes Miami-Dade County.

\footnotetext{
${ }^{10}$ County fixed effects were also considered, though the change in hospital-area spending levels within these eight years is not associated with changes in mortality. High-spending areas tend to remain so, with a spending measure defined on a county $\mathrm{x}$ year basis having a 1-year correlation of 0.95 . This paper focuses on the greater amount of variation in the cross section but among a visitor sample where the variation in local-area spending is more likely to be exogenous.
} 
The results show that the bottom quartile is one of the few sub-samples where little relationship is found between the local-area, end-of-life spending level and the mortality rate. This is the quartile least likely to be visited, as suggested by the lack of county-specific per-diem rates. The result may reflect the idiosyncratic nature of the patients who choose to visit these less popular counties—visitors who may be more likely to have longer-term ties to the area. Meanwhile, the top-3 quartiles have coefficients of 0.027, -0.056 , and -0.024 . $^{11}$ That is, the main results are found in the more popular destinations, even within areas with similar lodging prices-areas that are likely close demand substitutes where variation in the hospital-area spending levels are plausibly exogenous. $^{12}$

Another approach is to use controls for county characteristics from the U.S. Census. Controls included median household income in the county, 4 age-composition variables, a population variable, and 3 racial-composition variables. These variables were not statistically significant in predicting mortality in the model, and had little effect on the main coefficient of interest, as shown in Table 5.

A final set of destination controls included indicators for the types of visitors who frequent each destination. These data are from the 1995 American Travel Survey, as described in Section 3. These indicators are available for a subset of destinations spanning 24 counties. Controls included the fraction who were retired, the fraction who were on vacation (as opposed to business), 7 household income categories, and the

\footnotetext{
${ }^{11}$ When the quartiles were constructed based on the number of patients in each county, rather than the equal weights shown in Table 5, the coefficients are consistently negative as shown in the appendix.

${ }^{12}$ Another approach to compare similar destinations considered Spring Training sites for Major League Baseball. For these 13 counties during the first quarter, the coefficient on local-area, end-of-life spending is -0.033 (s.e. $=0.009, \mathrm{n}=8479$ ).
} 
fraction of visitors who are White. ${ }^{13}$ This model resulted in a somewhat larger coefficient of -0.048 (s.e. $=0.014$ ), though this is largely due to the sample of popular counties. When the ATS controls were not included in a model estimated on this subsample, the coefficient is -0.041 (s.e. $=0.007$ ). Meanwhile, little relationship is found between spending and mortality for less-popular counties that are not included in the ATS survey (coefficient of -0.002, $\mathrm{n}=7917$ ). As discussed above, less popular counties may be visited by individuals with particular ties to the area-individuals more like the local population.

In terms of the ATS covariates, Table 5 shows that areas that with higher-income visitors again tend to have higher mortality rates. Areas with more visitors who are retirees are associated with lower mortality rates.

\section{Additional Robustness Checks}

Other robustness results are reported in the appendix. In particular, when a probit model was estimated, the marginal effect of the local-area spending measure, evaluated at the mean of the covariates, was -0.027 (s.e.=0.007). Second, when the definition of the term "visitor" included any patient whose residence was more than 100 miles from the center of the hospital's county, this slightly larger sample of 40,701 has a similar coefficient of -0.031 (s.e. $=0.007$ ). The results are also robust to the definition of the local-area spending measure, both when using all (rather than end-of-life) emergency spending (coefficient of -0.035), and when using spending on heart emergencies among locals rather than all emergencies (coefficient of -0.023). Another robustness check included indicators for co-morbidities in the form of the Charlson severity index (Quan et

\footnotetext{
${ }^{13}$ The main results were similar when education, household size, and age categories were also included, though multicollinearity resulted in noisy estimates of the ATS covariates.
} 
al., 2005). The index took on values of 0,1 , and 2 , and including an indicator for each value did not change the main results with a coefficient on local-area spending intensity of -0.030 (s.e. $=0.007)$.

\section{Censoring due to Discharges to Other Facilities}

One issue when considering inpatient mortality is that patients may be transferred to another facility and the mortality measure is censored. When discharge to another facility was considered as an outcome, high-spending areas were not statistically significantly more likely to have such as discharge, and the coefficient suggested a negative relationship with the spending measure. ${ }^{14}$ This reflects more discharges home, possibly reflecting better health upon discharge or the use of hospital care to substitute for skilled nursing facilities or short-term hospitals. In any event, it does not appear that censoring due to patient transfers is driving the lower inpatient mortality rate found in the main results.

Overall, the results imply that patients who are far from home when they suffer from a life-threatening emergency have significantly lower inpatient mortality rates when they are treated in counties that tend to spend more on health care. This is found within similar types of visitors, within similar destinations, and the results are robust to estimation techniques. In addition, smaller returns are found in samples more likely to include long-term visitors, such as patients with chronic illnesses or visitors to destinations less popular for vacations—areas without county-specific per-diem rates and areas not included in the American Travel Survey. Given that long-term visitors may be more appropriately thought of as local residents, where the health care systems may be

\footnotetext{
${ }^{14}$ In a model of such a discharge with all controls, the coefficient is -0.10 (s.e.=0.06) compared to a mean of 0.20 . Results were qualitatively similar when the estimates were based on the local-area population: coefficient of -0.024 , s.e. $=0.035$, compared to a mean of 0.23 .
} 
designed in part for them and individuals are more likely to investigate health care quality when choosing the destination — these results suggest that any selection bias would tend to bias the estimates toward finding no relationship between mortality and spending as in panel A of Table 2.

\section{Interpretation}

Table 6 considers alternative measures of local-area inputs to test the robustness of the main results and to describe how high-spending counties differ from low-spending ones. The charge measure itself is considered, along with length of stay, procedure use, and staffing levels.

The first row considers a cost measure in an attempt to control for local-area prices and consider actual resource use. Each hospital reports a cost-to-charge ratio to the Centers for Medicare and Medicaid each year. The measure of local-area costs was constructed the same way as the local-area charge measure: the mean log costs for emergency patients who died in the hospital, where costs are simply the charges multiplied by each hospital's cost-to-charge ratio. One limitation is that these cost measures tend to be noisy. ${ }^{15}$

The local-area cost variable has a lower mean (9.19 vs. 9.98) than the charge measure and a smaller standard deviation ( 0.18 vs. 0.23 ). The measure is positively correlated with the charge measure, though less than 1 ( $\rho=0.67)$. In a model similar to (8), the coefficient on the local-area cost measure is -0.046 with a standard error of 0.013 .

\footnotetext{
${ }^{15}$ The results here substitute the median cost-to-charge ratio for outliers as suggested by CMS. In particular, the data are replaced when the cost-to-charge ratio for the hospital is in the top or bottom $2 \%$. Results were not sensitive to outlier definitions, including greater than plus-or-minus three standard deviations, as well as replacing the cost-to-charge ratio with the extreme values of the trimmed cost-tocharge ratios as opposed to the median.
} 
This implies that a two-standard deviation increase in the costs is associated with a 1.6 percentage-point drop in mortality, again $5 \%$ of the mean mortality rate. The results are consistent with differences stemming from differences in the quantity of care provided rather than differences in price.

Another way to explore the source of the main results is to consider the types of charges that may differ across counties. This is facilitated by revenue codes in the discharge data that break the total charges into categories such as intensive care or operating room charges. One caveat is that these revenue codes may be treated differently by hospital (and, therefore, by county), so the results should be taken with caution.

The local-area, end-of-life spending measure was calculated for each charge category and used in a separate regression model similar to (8). The appendix reports estimates for each revenue code, though the results can be summarized by four categories: surgical, diagnostic, intensive care, and other charges. Table 6 reports the estimates, and the main results appear to stem from greater than average spending on diagnostic procedures, intensive care, and the catch-all of other charges. ${ }^{16}$ The surgical charge measure is unrelated to mortality and has a positive coefficient. It is also the measure that is least related to local-area spending, with a correlation of 0.33 .

To further explore the role of surgical procedures, a number of tests were conducted regarding procedures performed. Among heart-emergency patients who died in the hospital, the fraction of locals that underwent a surgical procedure and the mean number of procedures were calculated. Both measures have positive coefficients in a

\footnotetext{
${ }^{16}$ Wennberg et al. (1996) also found that diagnostic procedures such as stress tests explain much of the variance in invasive cardiac procedure rates across service areas.
} 
model of mortality with full controls, though the estimates are not statistically significant. Similar results were found when the rate or number of surgical procedures was calculated for all heart-emergency patients rather than restricting the calculation to those who died in the hospital. ${ }^{17}$

These results are similar to the results in McClellan, McNeil and Newhouse (1994) and Stukel, Lucas, and Wennberg (2005) that areas with more intensive treatment had little gains from such treatment, though it contrasts with Stukel, et al. (2007) who found a $16 \%$ relative decrease in mortality due to invasive treatment—a paper that used the local-area likelihood of invasive treatment as an instrument for a given patient's treatment. ${ }^{18}$ Further, McClellan and Newhouse (1997) found that cardiac catheterization rates were modestly associated with better health outcomes, and that the benefits stemmed largely from "correlated beneficial technologies”, a result similar to the one found here where diagnostic and intensive care spending are related to mortality, but surgical charges are not.

A measure of resource use that is related to charges but more uniformly measured across counties is length of stay in the hospital. Areas with longer lengths of stay for those who eventually die in the hospital are found to have lower mortality rates for visitors. In a model of mortality, the coefficient on local-area, end-of-life length of stay

\footnotetext{
${ }^{17}$ In a separate analysis, volumes of coronary artery bypass surgeries and cardiac catheterizations were calculated and counties were broken into quartiles based on these counts. Counties that had particularly high volumes of local-area surgeries were associated with lower mortality rates compared to counties in the 2nd and 3rd quartiles.

${ }^{18}$ Sheehan-Connor (2007) used California discharge data and the rate of interventional therapy among California residents who entered hospitals with a heart attack 200 miles from their home as an instrument for such therapy among locals. That paper found a negative relationship between interventional therapy and mortality. The current paper takes the opposite approach by considering the assets available to visitors in a county to be endogenous to local-area patient characteristics but exogenous to visitor characteristics-a result supported by the medical literature (Fisher et al., 1994; Stukel, Lucas, Wennberg, 2005), as described in section 2 .
} 
is -0.056 (s.e. $=0.018$ ). For a two-standard deviation increase in this measure, this implies a 1.3 percentage-point drop in mortality.

Last, the main results appear to stem from “overall” spending, and this may be reflected in staffing levels and wage bills. To explore differences across counties, the American Hospital Association provides information about the number of physicians and nurses at each hospital. For each county, a physician-to-admission ratio and a nurse-toadmission ratio were calculated for the year 2000, as well as labor expenses in the county per full-time employee. These measures are not highly correlated with local-area, end-oflife charges, with correlations of $0.28,0.11$, and 0.24 , respectively. They are also unrelated to mortality with opposite signs and relatively large standard errors.

\section{Instrumental Variables Estimates}

Another way to summarize the main results is by considering the additional spending on the visitor population associated with an emergency in higher-spending areas. The change in mortality can then be normalized by this dollar amount to estimate the returns to spending. That is, a 2SLS model of mortality on patient charges can be estimated using the county spending measure as an instrument.

The first stage for patient $\mathrm{i}$ treated in county $\mathrm{c}$ from ZIP code $\mathrm{z}$ in state $\mathrm{s}$ in year $\mathrm{t}$ is:

(9) $T_{\text {iczst }}=\alpha_{0}+\alpha_{1} T_{c}+\alpha_{2} X_{i}+\alpha_{3} W_{z}+\alpha_{4} P_{c}+\theta_{s}+\delta_{t}+\mu_{\text {iczst }}$ and the second stage is:

$$
\text { (10) } M_{i c z s t}=\beta_{0}+\beta_{1} \hat{T}_{i c s t}+\beta_{2} X_{i}+\beta_{3} W_{z}+\beta_{4} P_{c}+\theta_{s}+\delta_{t}+\varepsilon_{i c s s t}
$$

Identification of $\beta_{1}$ relies on the mean independence of $\mathrm{T}_{\mathrm{c}}$ and $\varepsilon$. Earlier results showed that the reduced-form results were similar within areas that appear to be close 
demand substitutes, and that the results were not sensitive to the addition of controls for patient and area characteristics. These robustness results are suggestive that the visitors are not choosing the destination based on the health care-spending level and provides some evidence that the local-area spending level is exogenous to the patient's mortality risk. That said, differences in local-area spending likely reflect other differences in the area, including differences in medical technology and staff experience that may not be fully reflected in the spending on visitors in the hospital.

Table 7 reports the instrumental-variable (IV) results using the charge measure and the cost measure described above. Panel A shows that the first stage yields coefficients on local-area spending and local-area costs on the order of 0.7 and 0.65 . These estimates show that visitor spending is highly associated with end-of-life spending on locals, though less than a one-for-one relationship. F-statistics on the excluded instrument are close to 50 when charges are considered and 16 when the noisier cost measures are used, well above the usual rule of thumb of 10 for weak instruments (Stock, Wright, and Yogo, 2002).

Panel B reports the two-stage least squares results for the inpatient mortality outcome. When charges are considered, the coefficient is -0.043 , with little change with or without controls. For costs, the coefficient is -0.080 without controls and -0.069 with controls. For the 25 log point difference shown in Table 1, these estimates imply mortality rate reductions of 1 and 1.8 percentage points, respectively.

These are large reductions in mortality attributed to the difference in spending on the patient, though other studies have found large effects. For example, Taylor et al. 
(1999) found that teaching hospitals have 20-50\% higher costs compared to for-profit and government hospitals, but also had a $25 \%$ lower mortality rate.

To evaluate the size of these effects, a back-of-the-envelope calculation of the marginal cost of a statistical life-year saved can be considered. Among heart emergencies, a $1 \%$ increase in charges compared to the median is roughly $\$ 140$. Meanwhile, the average age in the sample is 70 years old, and 70-year-olds have a life expectancy of 85 years old (Arias, 2007). This patient population is in worse health, however, so assuming an additional 7 years of life for those who survive the hospital stay, the IV estimates imply a cost of saving a statistical life year on the order of $\$ 47,000 .{ }^{19}$ The number would be lower if the cost measure were considered, though the facility charges do not include physician fees, which are similar in magnitude to the difference between costs and charges.

Further, the results in Table 3 suggest that this increase in spending is found for all emergency patients. When a 2SLS model for all emergencies is considered with three-digit primary diagnosis fixed effects included as well, the first-stage coefficient is 0.59 (s.e. $=0.009$ ) and the coefficient on instrumented charges is -0.029 (s.e. $=0.008$ ). For costs the coefficient is -0.039 (s.e. $=0.018$ ). This sample has slightly lower median charges, so a $1 \%$ increase is on the order of $\$ 100$. This implies a cost per statistical lifeyear of $\$ 49,000$ in charges. ${ }^{20}$

By comparison, McClellan and Newhouse (1997) used a difference-in-differences strategy comparing adopting and non-adopting hospitals in terms of invasive treatments

\footnotetext{
${ }^{19} \$ 140 /(0.043 * 0.01)$ divided by $7=\$ 46,500$. The analogous calculation for the cost measure is $\$ 65 /(0.069 * 0.01)$ divided by $7=\$ 13,000$.

${ }^{20}$ The calculation is $\$ 100 /(0.029 * 0.01)$ divided by $7=\$ 49,000$. For costs: $\$ 50 /(0.039 * 0.01)$ divided by 7

$=\$ 18,000$.
} 
of heart attacks and found a $\$ 70,000$ cost for a statistical life year saved. Cutler, Rosen and Vijan found a \$145,000 cost per life year gained for elderly patients between 1990 and 2000. The value of an additional life year in good health is typically set at $\$ 100,000$ (Cutler and McClellan, 2001). Although the back-of-the-envelope calculations here are sensitive to the assumptions, the additional cost per statistical life year saved appears to be below the estimated benefit.

The above estimates relate most directly to visitors, though greater amounts are spent on locals as well. If the estimated returns to visitors reflect the returns to locals (a return that is masked in the regression on the local population due to confounding factors), then the cost of saving a statistical life would be similar among local patients.

There are a number of limitations to this type of analysis. It may be that individuals that visit high-spending areas differ from those who visit low-spending areas, though the usual selection bias of sicker patients seeking higher-quality hospital care would tend to bias the results in favor of finding no (or a positive) relationship between spending and mortality. Further, the visitor group may be expected to be more active than locals given that they made the trip and may be particularly suitable for higher treatment intensity. The mortality rates for the local and visitor populations are similar, however, suggesting that this group is informative of the returns to spending even outside of this traveling group.

Another limitation is that the visitor status relies on the state of residence claimed by the patient, and there may be measurement error. This is a problem particular to Florida where many retirees spend a winters in Florida. In general, long-term visitors to Florida have a tax advantage of claiming Florida as the primary residence (Lannon, 2006). 
In addition, the results in section 5 suggest that a selection bias would tend to bias the estimates toward zero, similar to the local-area population estimates.

\section{Conclusions}

Estimating the returns to health care spending is necessary to evaluate our health care system but is complicated by the fact that individuals in worse health receive more care. In fact, there is a strong positive correlation between spending and mortality at the individual level. Aggregating to the regional level, areas that spend more may also have patients in worse health, which can confound comparisons, and the results here replicated earlier findings of little relationship between spending and mortality among the populations the health care systems were designed to serve.

In contrast, those who have a serious health emergency far from home are exposed to different health care systems and are unlikely to impact the resources available in these systems. The results imply that if the emergency occurred in a highspending area, the patient was significantly more likely to survive. These results were found within groups of counties that are popular destinations with similar lodging prices—areas that are likely to be close demand substitutes in terms of vacation destinations to provide plausibly exogenous variation in health care systems.

In particular, areas that spend more on local patients tend to spend more on visitors as well, and the additional cost of a statistical life year saved is found to be on the order of $\$ 50,000$ — well below the typical value of life year saved of $\$ 100,000$. Smaller returns were found in sub-samples where the visitors were more likely to select the 
destination with the health care system in mind, suggesting that the main results may understate the benefits to health care spending. 


\section{References}

Arias, Elizabeth. (2007) “United States Life Tables, 2003.” National Vital Statistics Reports. 54(14). Original April 19, 2006; Revised March 28, 2007.

Baicker.Katherine and Amitabh Chandra. (2004) "Medicare Spending, the Physician Workforce, and the Quality of Care Received by Medicare Beneficiaries,” Health Affairs W4: 184-197.

Cao, Zhun and Thomas G. McGuire. (2003) "Service-Level Selection by HMOs in Medicare” Journal of Health Economics 22(6): 915-31.

Catlin, Aaron, Cowan, Cathy, Heffler, Stephen, and Benjamin Washington. (2007) “National Health Spending In 2005: The Slowdown Continues.” Health Affairs, 26(1): 142-153.

Chandra, Amitabh, and Douglas O. Staiger. (2007) "Productivity Spillovers in Health Care: Evidence from the Treatment of Heart Attacks.” Journal of Political Economy. 115(1): 103-140.

Cutler, David.M., and Mark B. McClellan. (2001) "Is technological change in medicine worth it?” Health Affairs 20(5): 11-29.

Cutler, David M., McClellan, Mark B., Newhouse, Joseph P. and Dahlia Remler. (1998) “Are medical prices declining? Evidence for heart attack treatments” Quarterly Journal of Economics 113(4): 991-1024.

Cutler, David M., Rosen, Allison B., Vijan, Sandeep. (2006) “The Value of Medical Spending in the United States, 1960-2000” New England Journal of Medicine. 355: 920-927

Dobkin, Carlos. “Hospital Staffing and Inpatient Mortality” Working Paper. June 2003.

Enthoven, Alain C. Health Plan. Reading, MA: Addison-Wesley. 1980.

Fisher, Elliot S. and H. Gilbert Welch. (1999) “Avoiding the Unintended Consequences of Growth in Medical Care: How Might More Be Worse?" Journal of the American Medical Association. 281: 446-453.

Fisher E, Wennberg D, Stukel T, Gottlieb D, Lucas F, Pinder E. (2003) "Implications of regional variations in Medicare spending. part 2: health outcomes and satisfaction with care.” Annals of Internal Medicine 138(4): 288-298.

Fisher, Elliott S., Wennberg, John E., Stukel, Therese A., Sharp, Sandra M. (1994) "Hospital Readmission Rates for Cohorts of Medicare Beneficiaries in Boston and New Haven” New England Journal of Medicine. 331: 989-995. 
Fuchs, Victor R. (2004) "More Variation in Use of Care, More Flat-of-the-curve Medicine.” Health Affairs. 23(6): 104-107.

Gowrisankaran, Gautam and Robert J. Town (1999). "Estimating the Quality of Care in Hospitals Using Instrumental Variables,” Journal of Health Economics 18: 747 67.

Guadagnoli, Edward, Hauptman, Paul J., Ayanian, John Z., Pashos, Chris L., McNeil, Barbara J., Cleary, Paul D. (1995) "Variation in the Use of Cardiac Procedures after Acute Myocardial Infarction.” New England Journal of Medicine. 333: 573578.

Heidenreich, P.A. and M. McClellan. (2001) "Trends in treatment and outcomes for acute myocardial infarction: 1975-1995.” American Journal of Medicine 110: 165-174.

Institute of Medicine, Unequal Treatment: Confronting Racial and Ethnic Disparities in Health Care, National Academy Press, Washington, DC (2002).

Kessler, Daniel and Mark McClellan. (1996) “Do Doctors Practice Defensive Medicine?” The Quarterly Journal of Economics. 111(2): 353-390.

Lannon, Patrick J. (2006) “Domicile Planning — Don’t Take it for Granted.” The Florida Bar Journal. 80(1): 34.

Lee, Ronald, and Jonathan Skinner. (1999) “Will Aging Baby Boomers Bust the Federal Budget?” The Journal of Economic Perspectives, 13(1): 117-140.

Luce, B.R., Mauskopf, J., Sloan, F.A., Ostermann, J., \& Paramore, C. (2006). “The return on investment in health care: from 1980 to 2000.” Value in Health, 9 (3):146-156.

McClellan, Mark B., McNeil, J. and Joseph P. Newhouse. (1994) “Does more intensive treatment of acute myocardial infarction in the elderly reduce mortality? Analysis using instrumental variables.” Journal of the American Medical Association. 272: 859-866

McClellan, Mark B., and Joseph P. Newhouse. (1997) "The Marginal Cost-Effectiveness of Medical Technology: A Panel Instrumental-Variables Approach." Journal of Econometrics 77: 39-64.

McGuire, T.G. and R. P. Ellis. "Provider Behavior Under Prospective Reimbursement." Journal of Health Economics. 5. 1986: 129-151

Murphy, Kevin M. and Robert Topel. (2003) “The Economic Value of Medical Research” in Kevin M. Murphy and Robert H. Topel (Eds.), Measuring the Gains 
from Medical Research: An Economic Approach Chicago: University of Chicago Press.

Nordhaus, William D. (2002) "The Health of Nations: The Contribution of Improved Health to Living Standards" NBER Working Paper No. 8818.

O’Connor, Gerald T., Quinton, Hebe B., Traven, Neal D., Ramunno, Lawrence D., Dodds, T. Andrew, Marciniak, Thomas A., and John E. Wennberg. (1999) "Geographic Variation in the Treatment of Acute Myocardial Infarction: The Cooperative Cardiovascular Project” Journal of the American Medical Association. 281: 627-633.

Pilote, Louise, Califf, Robert M., Sapp, Shelly, Miller, Dave P., Mark, Daniel B., Weaver, W. Douglas, Gore, Joel M., Armstrong, Paul W., Ohman, E. Magnus, and Eric J. Topol. (1995) "Regional Variation across the United States in the Management of Acute Myocardial Infarction” New England Journal of Medicine. 333: 565572.

Quan H, Sundararajan V, Halfon P, Fong A, Burnand B, Luthi JC, Saunders LD, Beck CA, Feasby TE, and WAGhali. (2005) "Coding algorithms for defining comorbidities in ICD-9-CM and ICD-10 administrative data." Medical Care 43(11):1073-1077.

Sheehan-Connor, Damien. "Traveler Experience as an Instrument to Assess Medical Care Effectiveness.” Working Paper. February 2007.

Sirovich BE, Gottlieb DJ, Welch HG, and ES Fisher. (2006) Regional variations in health care intensity and physician perceptions of the quality of care. Annals of Internal Medicine. 144: 641-649.

Stock, James, James Wright, and Motohiro Yogo. (2002). “A Survey of Weak Instruments and Weak Identification in GMM.” Journal of Business and Economic Statistics, 20:4, 518-29.

Stukel, Therese A., Fisher, Elliott S., Wennberg, David E., Alter, David A., Gottlieb, Daniel J., and Marian J. Vermeulen. (2007) “Analysis of Observational Studies in the Presence of Treatment Selection Bias: Effects of Invasive Cardiac Management on AMI Survival Using Propensity Score and Instrumental Variable Methods.” Journal of the American Medical Association 297: 278-285.

Stukel, Therese A., Lucas, F. Lee, and David E. Wennberg. (2005) "Long-term Outcomes of Regional Variations in Intensity of Invasive vs Medical Management of Medicare Patients With Acute Myocardial Infarction” Journal of the American Medical Association. 293: 1329-1337 
Taylor, Donald H., Whellan, David J., and Frank A. Sloan. (1999) "Effects of Admission to a Teaching Hospital on the Cost and Quality of Care for Medicare Beneficiaries" New England Journal of Medicine 340: 293-299.

Tu, Jack V., Pashos, Chris L., Naylor, C. David, Chen, Erluo, Normand, Sharon-Lise, Newhouse, Joseph P., and Barbara J. McNeil. (1997) "Use of Cardiac Procedures and Outcomes in Elderly Patients with Myocardial Infarction in the United States and Canada” New England Journal of Medicine. 336: 1500-1505.

Wennberg, D. E., Kellett, M. A., Dickens, J. D., Malenka, D. J., Keilson, L. M., and R. B. Keller (1996) "The association between local diagnostic testing intensity and invasive cardiac procedures.” Journal of the American Medical Association. 275: $1161-1164$. 
Figure 1:

Potential Mortality-Treatment Relationship Across Populations that Differ by Their Underlying Risk

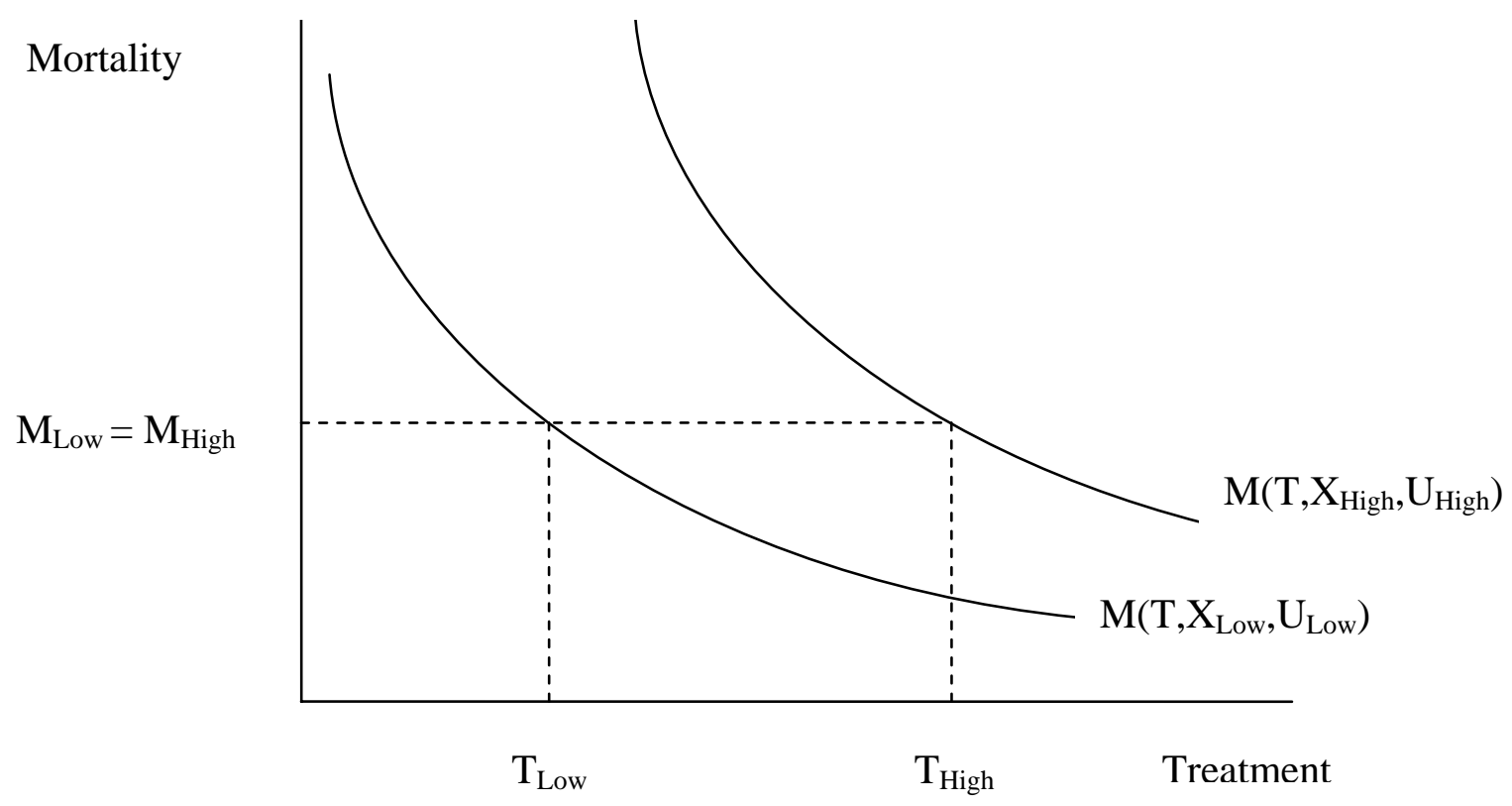


Table 1: Patients with Heart Emergencies: Locals vs. Visitors to Florida (Selected Variables)

\begin{tabular}{|c|c|c|c|c|c|c|c|}
\hline \multirow{2}{*}{$\begin{array}{l}\text { Variable } \\
\end{array}$} & \multirow[t]{2}{*}{ Patient Group: } & \multicolumn{2}{|c|}{ Floridians } & \multicolumn{2}{|c|}{$\frac{\text { Low-Spending County }}{\text { Visitors }}$} & \multicolumn{2}{|c|}{$\frac{\text { High-Spending County }}{\text { Visitors }}$} \\
\hline & & Mean & Std Dev & Mean & Std Dev & Mean & Std Dev \\
\hline \multicolumn{8}{|l|}{ Local-area level: } \\
\hline Treatment & mean log(charges) | mortality & 10.01 & 0.23 & 9.79 & 0.15 & 10.16 & 0.12 \\
\hline \multicolumn{8}{|l|}{ Patient-level: } \\
\hline \multirow[t]{2}{*}{ Treatment } & hospital charges & 22328 & 30706 & 20776 & 26060 & 26997 & 35864 \\
\hline & $\log ($ charges) & 9.59 & 0.86 & 9.51 & 0.88 & 9.75 & 0.91 \\
\hline Outcome & Mortality & 0.057 & 0.23 & 0.061 & 0.24 & 0.054 & 0.23 \\
\hline \multirow{3}{*}{$\begin{array}{l}\text { Personal } \\
\text { Characteristics }\end{array}$} & Male & 0.52 & 0.50 & 0.63 & 0.48 & 0.62 & 0.49 \\
\hline & & & & & & & \\
\hline & Age & 71.8 & 14.2 & 71.6 & 11.9 & 68.8 & 13.4 \\
\hline Payer & Medicare & 0.56 & 0.50 & 0.66 & 0.47 & 0.51 & 0.50 \\
\hline \multirow[t]{5}{*}{ Categories } & Medicare HMO & 0.14 & 0.35 & 0.04 & 0.19 & 0.05 & 0.23 \\
\hline & Medicaid & 0.05 & 0.21 & 0.01 & 0.09 & 0.02 & 0.13 \\
\hline & Private Insurance & 0.19 & 0.39 & 0.24 & 0.43 & 0.32 & 0.47 \\
\hline & Other insurance & 0.02 & 0.13 & 0.01 & 0.10 & 0.01 & 0.11 \\
\hline & Uninsured & 0.04 & 0.21 & 0.04 & 0.19 & 0.08 & 0.28 \\
\hline \multirow[t]{3}{*}{ Race } & African American & 0.11 & 0.32 & 0.02 & 0.15 & 0.06 & 0.23 \\
\hline & Hispanic & 0.11 & 0.32 & 0.01 & 0.09 & 0.07 & 0.26 \\
\hline & White & 0.75 & 0.43 & 0.95 & 0.22 & 0.84 & 0.37 \\
\hline ZIP Code of & Median HH Income & 37450 & 10638 & 51031 & 20395 & 49362 & 18967 \\
\hline Residence & Fraction College Grad & 0.21 & 0.10 & 0.28 & 0.17 & 0.27 & 0.16 \\
\hline \multirow[t]{2}{*}{ Characteristics } & Fraction white & 0.65 & 0.28 & 0.83 & 0.18 & 0.79 & 0.22 \\
\hline & Population & 28023 & 13630 & 22526 & 16311 & 25859 & 19330 \\
\hline \multirow{5}{*}{$\begin{array}{l}\text { Emergency } \\
\text { Characteristics }\end{array}$} & 1st Quarter & 0.27 & 0.45 & 0.50 & 0.50 & 0.44 & 0.50 \\
\hline & 2nd Quarter & 0.24 & 0.43 & 0.21 & 0.40 & 0.21 & 0.41 \\
\hline & 3rd Quarter & 0.23 & 0.42 & 0.11 & 0.31 & 0.13 & 0.34 \\
\hline & 4th Quarter & 0.26 & 0.44 & 0.19 & 0.39 & 0.21 & 0.41 \\
\hline & Weekend & 0.27 & 0.45 & 0.28 & 0.45 & 0.29 & 0.45 \\
\hline Area & Per-diem in January & 109.29 & 16.67 & 113.41 & 23.61 & 107.62 & 14.64 \\
\hline Prices & Per-diem in July & 100.63 & 13.46 & 97.14 & 14.02 & 102.37 & 12.73 \\
\hline \multirow{2}{*}{$\begin{array}{l}\text { Summary of } \\
\text { Covariates }\end{array}$} & Predicted Mortality & - & - & 0.058 & 0.03 & 0.058 & 0.03 \\
\hline & Observations & 753645 & & 18066 & & 18661 & \\
\hline \multicolumn{8}{|c|}{$\begin{array}{l}\text { Patients with an emergency admission for heart disease in Florida, 1996-2003. Spending areas defined by median of } \\
\text { the local-area treatment measure: mean log charges conditional on mortality for the county. Predicted Mortality is } \\
\text { estimated from a probit model on the full set of controls including indicators for each age, day of the week, and year. } \\
\text { Means for the ZIP Code characteristics include only patients with ZIP code information, which excludes those who } \\
\text { primary residence is outside the U.S., resulting in sample sizes of 15,898 in low-spending areas and 14,177 in the } \\
\text { high-spending area. }\end{array}$} \\
\hline
\end{tabular}


Table 2: Treatment \& Health Outcomes for Heart Emergencies

\section{A. Florida Locals}

Dependent Variable: Mortality

$\log$ (charges)

\begin{tabular}{|c|c|c|c|c|c|c|c|}
\hline (1) & (2) & (3) & (4) & (5) & (6) & (7) & (8) \\
\hline $\begin{array}{c}0.025 \\
(0.003) \\
\end{array}$ & $\begin{array}{c}0.027 \\
(0.002)\end{array}$ & $\begin{array}{c}0.027 \\
(0.002)\end{array}$ & $\begin{array}{c}0.027 \\
(0.002)\end{array}$ & & & & \\
\hline & & & & $\begin{array}{c}0.001 \\
(0.004) \\
\end{array}$ & $\begin{array}{r}0.005 \\
(0.005) \\
\end{array}$ & $\begin{array}{c}0.005 \\
(0.005) \\
\end{array}$ & $\begin{array}{c}0.002 \\
(0.003) \\
\end{array}$ \\
\hline No & Yes & Yes & Yes & No & Yes & Yes & Yes \\
\hline No & No & Yes & Yes & No & No & Yes & Yes \\
\hline No & No & No & Yes & No & No & No & Yes \\
\hline
\end{tabular}

Controls for Patient ZIP Code Characteristics

Controls for Area Prices

753645

Observations
Mean of Dep. Variable

0.057

\section{B. Visitors}

Dependent Variable: Mortality

$\log ($ charges)

local area: mean $\log$ (charges) $\mid$ mortality

Controls for Personal Characteristics

Controls for Patient ZIP Code Characteristics

Controls for Area Prices

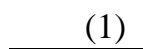

$$
\text { (1) }
$$

0.028

(3)

0.028

(4)

(6)

(7)

Observations

$\begin{array}{llll}(0.002) & (0.002) & (0.002) & (0.002)\end{array}$

Mean of Dep. Variable

\begin{tabular}{cccccccc} 
& & & & $(0.009)$ & $(0.008)$ & $(0.008)$ & $(0.008)$ \\
\hline No & Yes & Yes & Yes & No & Yes & Yes & Yes \\
No & No & Yes & Yes & No & No & Yes & Yes \\
No & No & No & Yes & No & No & No & Yes \\
\hline
\end{tabular}

36727

Regressions with local-area measures: standard errors are clustered at the county level. Personal characteristics include the variables in Table 1, including indicators for each age, day of the week, and year. 
Table 3: Results for Frequent Diagnoses \& Across Illness Severity

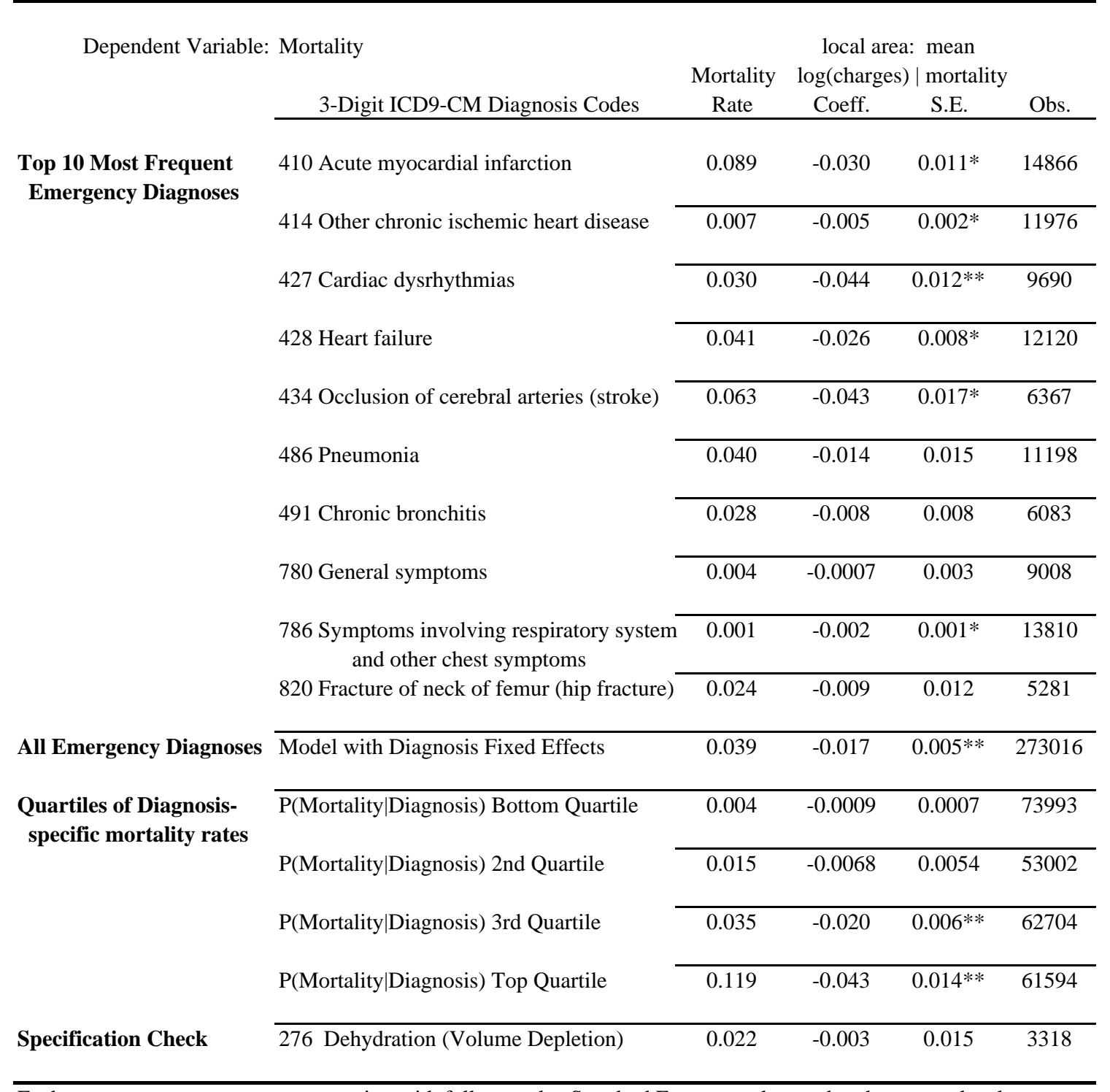

Each row represents a separate regression with full controls. Standard Errors are clustered at the county level. $\mathrm{P}($ Mortality|Diagnosis) is predicted mortality from a probit model with 3-digit primary diagnosis indicators (for diagnoses with at least 10 observations and at least one fatality). Models for each diagnosis-specific mortality quartile include 3digit, primary diagnosis fixed effects as well. Each sub-sample is restricted to patients from states with at least 5 observations. $*=5 \%$; **=1\%. 
Table 4: Heart Emergency Results Across Patient Types

Dependent Variable: Mortality

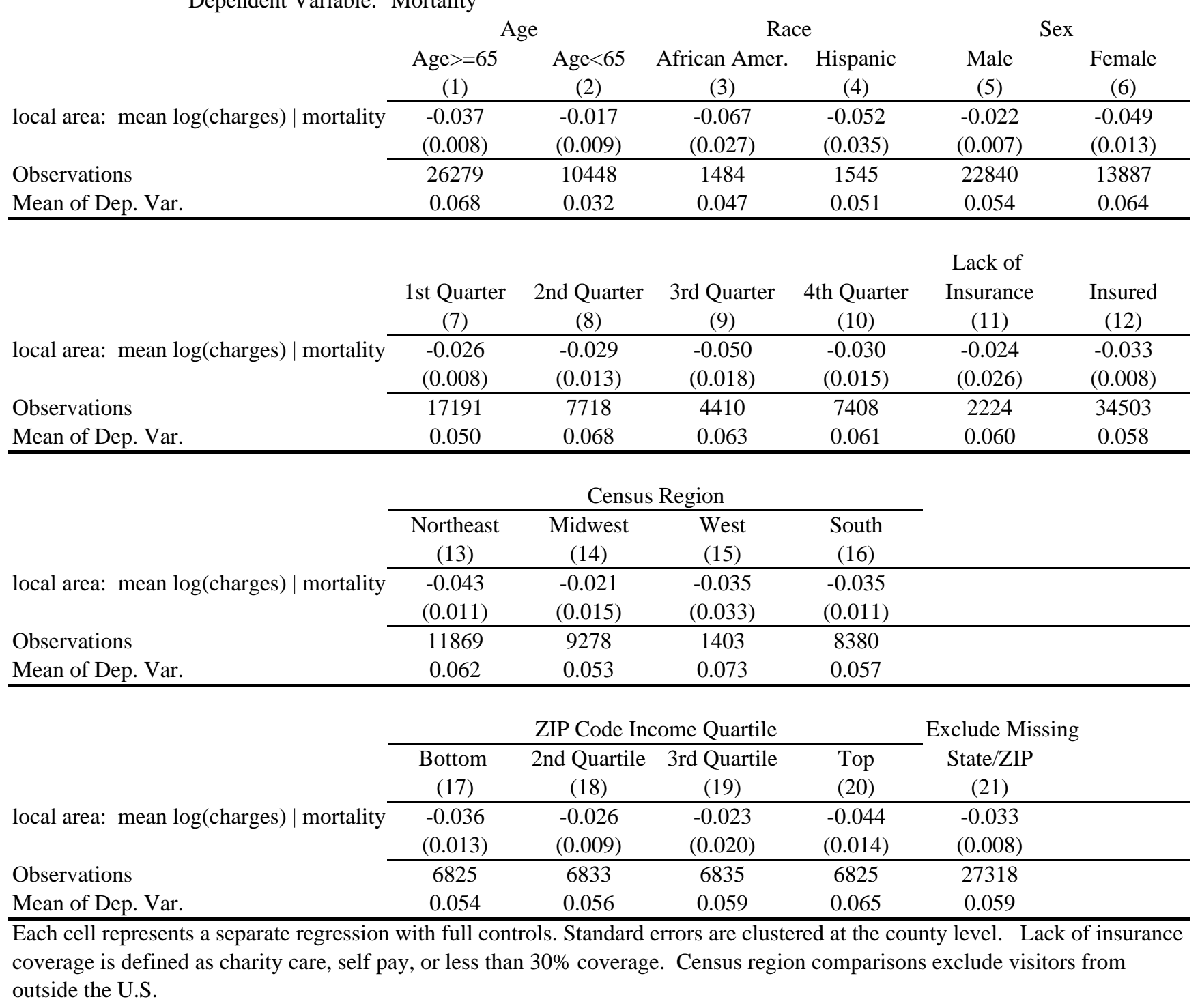


Table 5: Heart Emergency Results Across County Types

Dependent Variable: Mortality

Destination Demand Substitutes: Visitor Price Quartiles

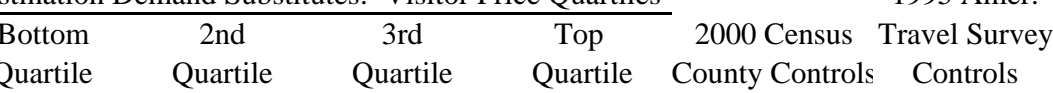

local area: mean $\log ($ charges $) \mid$ mortality

(2)

$-0.023$

(4) $-0.030$ (6)

American Travel Survey Variables

$(0.007)^{*}$

$(0.012)^{*}$

$-0.048$ (fraction of visitors):

\begin{tabular}{|c|c|c|c|c|c|c|}
\hline Family income $>=\$ 15 \mathrm{k} \&<\$ 25 \mathrm{k}$ & & & & & & $\begin{array}{c}0.113 \\
(0.080)\end{array}$ \\
\hline Family income $>=\$ 25 \mathrm{k} \&<\$ 30 \mathrm{k}$ & & & & & & $\begin{array}{l}-0.067 \\
(0.164) \\
\end{array}$ \\
\hline Family income $>=\$ 30 \mathrm{k} \&<\$ 40 \mathrm{k}$ & & & & & & $\begin{array}{c}-0.634 \\
(0.148)^{* *}\end{array}$ \\
\hline Family income $>=\$ 40 \mathrm{k} \&<\$ 50 \mathrm{k}$ & & & & & & $\begin{array}{c}-0.455 \\
(0.138)^{* *}\end{array}$ \\
\hline Family income $>=\$ 50 \mathrm{k} \&<\$ 60 \mathrm{k}$ & & & & & & $\begin{array}{c}0.427 \\
(0.114)^{* *}\end{array}$ \\
\hline Family income $>=\$ 60 \mathrm{k} \&<\$ 75 \mathrm{k}$ & & & & & & $\begin{array}{c}0.910 \\
(0.299) * *\end{array}$ \\
\hline Family income $>=\$ 75 \mathrm{k} \&<\$ 100 \mathrm{k}$ & & & & & & $\begin{array}{c}-1.159 \\
(0.246) * *\end{array}$ \\
\hline Family income $>=\$ 100 \mathrm{k}$ & & & & & & $\begin{array}{c}0.462 \\
(0.147)^{* *}\end{array}$ \\
\hline Retired & & & & & & $\begin{array}{c}-0.180 \\
(0.028) * *\end{array}$ \\
\hline Vacation & & & & & & $\begin{array}{l}-0.034 \\
(0.033)\end{array}$ \\
\hline White & & & & & & $\begin{array}{l}-0.062 \\
(0.109)\end{array}$ \\
\hline Number of Counties & 17 & 10 & 8 & 9 & 44 & 24 \\
\hline Dbservations & 4517 & 6795 & 7160 & 18255 & 36727 & 28810 \\
\hline Mean of Dep. Var. & 0.069 & 0.057 & 0.060 & 0.055 & 0.058 & 0.058 \\
\hline
\end{tabular}

Each column represents a separate regression with full controls. Standard errors are clustered at the county level. Visitor prices are per-diem rates calculated by the US General Services Administration. The bottom quartile represents the counties that do not have their own per-diem rate. Census controls include race \& age composition, median income, and population at the county level. * $=$ significant at $5 \% ; * *=$ significant at $1 \%$ 
Table 6: Alternative Measures of Local-Area Inputs among Heart Emergencies

\begin{tabular}{|c|c|c|c|c|}
\hline & & $\begin{array}{c}\text { Mean of Measure } \\
\text { (Std. Dev.) }\end{array}$ & $\begin{array}{l}\text { Correlation with Local } \\
\log \text { (charges)|mortality }\end{array}$ & $\begin{array}{l}\text { Coefficient (s.e.) from } \\
\text { model of Mortality }\end{array}$ \\
\hline & Local Area Measures: & & & \\
\hline \multirow[t]{5}{*}{ Spending } & $\log ($ costs $) \mid$ mortality & $\begin{array}{c}9.19 \\
(018)\end{array}$ & 0.67 & $\begin{array}{l}-0.046 \\
0.013)\end{array}$ \\
\hline & $\log ($ surgical charges) $\mid$ mortality & $\begin{array}{c}7.38 \\
(0.29)\end{array}$ & 0.33 & $\begin{array}{c}0.007 \\
(0.006)\end{array}$ \\
\hline & $\log ($ diagnostic charges) $\mid$ mortality & $\begin{array}{c}8.41 \\
(0.30) \\
\end{array}$ & 0.88 & $\begin{array}{l}-0.021 \\
(0.006)\end{array}$ \\
\hline & log(icu charges) | mortality & $\begin{array}{c}8.03 \\
(0.25)\end{array}$ & 0.70 & $\begin{array}{l}-0.016 \\
(0.009)\end{array}$ \\
\hline & $\log$ (other charges) $\mid$ mortality & $\begin{array}{c}9.19 \\
(0.22)\end{array}$ & 0.90 & $\begin{array}{c}-0.023 \\
(0.010)\end{array}$ \\
\hline Length of Stay & $\log$ (length of stay) $\mid$ mortality & $\begin{array}{c}1.37 \\
(0.12)\end{array}$ & 0.49 & $\begin{array}{l}-0.056 \\
(0.018)\end{array}$ \\
\hline \multirow[t]{2}{*}{ Procedures } & invasive procedure rate | mortality & $\begin{array}{c}0.33 \\
(0.07)\end{array}$ & 0.44 & $\begin{array}{c}0.037 \\
(0.031)\end{array}$ \\
\hline & mean number of procedures | mortality & $\begin{array}{c}2.38 \\
(0.42) \\
\end{array}$ & 0.40 & $\begin{array}{c}0.006 \\
(0.005)\end{array}$ \\
\hline \multirow[t]{3}{*}{ Staffing } & physicians per 1000 admissions & $\begin{array}{c}1.08 \\
(1.42) \\
\end{array}$ & 0.28 & $\begin{array}{l}0.0006 \\
(0.001) \\
\end{array}$ \\
\hline & nurses per 1000 admissions & $\begin{array}{c}25 \\
(5.6)\end{array}$ & 0.11 & $\begin{array}{l}-0.0004 \\
(0.0004)\end{array}$ \\
\hline & labor expenses per full-time employee & $\begin{array}{c}42903 \\
6368\end{array}$ & 0.24 & $\begin{array}{c}1.42 \mathrm{e}-07 \\
(4.76 \mathrm{e}-07)\end{array}$ \\
\hline
\end{tabular}

Each row represents a separate regression with full controls and 36,727 observations. Standard Errors are clustered at the county leve] Column (1) reports the mean (standard deviation) of the alternative measure. Column (2) reports the correlation between the alternati measure and local area, mean log charges conditional on mortality. Costs are calculated as charges*hospital cost-to-charge ratio. Surgical charges include operating room, anesthesia, recovery room, and cardiology charges. Diagnostic charges include laboratory, pathology laboratory, diagnostic radiology, ct scan, and mri charges; Intensive care charges include coronary care unit charges as well as general ICU charges. 
Table 7A: Visitor Treatment Measures \& Local Area Treatment Measures

\begin{tabular}{|c|c|c|c|c|}
\hline \multirow[t]{2}{*}{ Dependent Variable: } & \multicolumn{2}{|c|}{$\log ($ charges $)$} & \multicolumn{2}{|c|}{$\log (\mathrm{costs})$} \\
\hline & $(1)$ & $(2)$ & $(3)$ & $(4)$ \\
\hline local area: mean $\log ($ charges $) \mid$ mortality & $\begin{array}{c}0.704 \\
(0.100) \\
\end{array}$ & $\begin{array}{c}0.742 \\
(0.100) \\
\end{array}$ & & \\
\hline local area: mean $\log ($ costs $) \mid$ mortality & & & $\begin{array}{c}0.656 \\
(0.158)\end{array}$ & $\begin{array}{c}0.642 \\
(0.160)\end{array}$ \\
\hline Full Controls & No & Yes & No & Yes \\
\hline F-statistic & 49.91 & 55.58 & 17.13 & 16.02 \\
\hline Observations & 36727 & & 36727 & \\
\hline Mean of Dep. Variable & 9.63 & & 8.86 & \\
\hline
\end{tabular}

Table 7B: 2SLS: Treatment \& Mortality

\begin{tabular}{|c|c|c|c|c|c|}
\hline & lent Variable: & \multicolumn{2}{|c|}{ Mortality } & \multicolumn{2}{|c|}{ Mortality } \\
\hline & & $(1)$ & $(2)$ & (3) & $(4)$ \\
\hline & log(charges) & $\begin{array}{c}-0.046 \\
(0.016) \\
\end{array}$ & $\begin{array}{l}-0.043 \\
(0.014) \\
\end{array}$ & & \\
\hline & $\log ($ costs $)$ & & & $\begin{array}{c}-0.080 \\
(0.032)\end{array}$ & $\begin{array}{l}-0.069 \\
(0.035)\end{array}$ \\
\hline Full Controls & & No & Yes & No & Yes \\
\hline Observations & & 36727 & & 36727 & \\
\hline Mean of Dep. Variable & & 0.058 & & 0.058 & \\
\hline
\end{tabular}

Each cell represents a separate regression with full controls. Standard Errors are clustered at the county level.

Columns (3) and (4) use a cost measure calculated as charges*hospital cost-to-charge ratio. 
Table A1: Reduced-Form Estimates with (Selected) Covariates

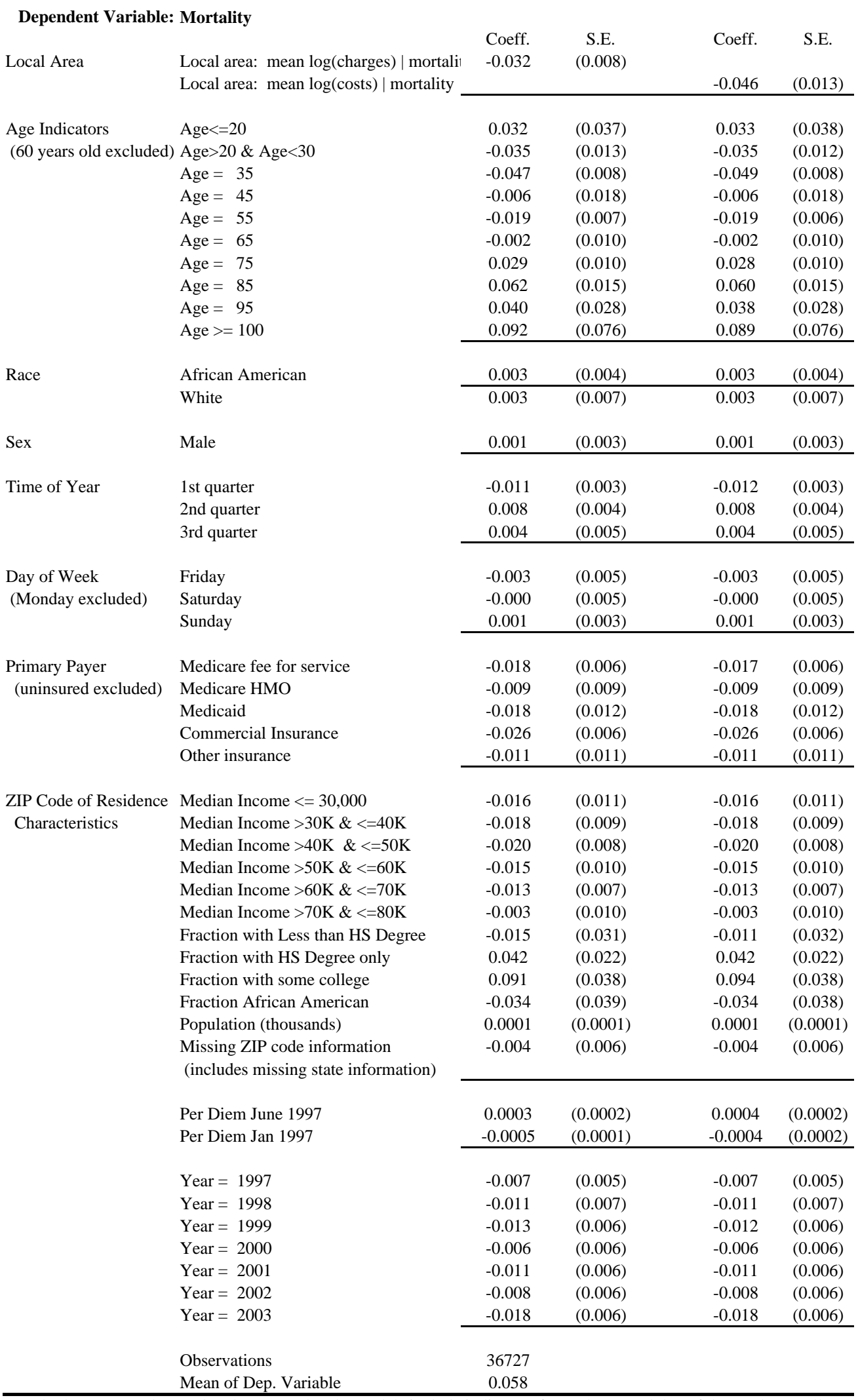

Standard errors are clustered at the county level. Models include indicators for each age and day of the week as well. 
Table A2: Robustness

\begin{tabular}{|c|c|c|c|c|c|c|c|c|}
\hline \multirow{3}{*}{$\begin{array}{l}\text { Patient or Local-Area treatment measure: } \\
\text { charge measure }\end{array}$} & \multicolumn{4}{|c|}{ Estimation } & \multicolumn{4}{|c|}{ County Per-Diem Quartiles (Patient Weighted } \\
\hline & $\begin{array}{c}\text { Probit } \\
(1)\end{array}$ & $\begin{array}{c}\text { Probit } \\
(2)\end{array}$ & $\begin{array}{l}\text { IV Probit } \\
\text { (3) }\end{array}$ & $\begin{array}{l}\text { IV Probit } \\
(4)\end{array}$ & $\begin{array}{c}\text { Bottom } \\
\text { Quartile } \\
(5)\end{array}$ & $\begin{array}{c}\text { 2nd } \\
\text { Quartile } \\
\text { (6) }\end{array}$ & $\begin{array}{c}\text { 3rd } \\
\text { Quartile } \\
(7)\end{array}$ & $\begin{array}{c}\text { Top } \\
\text { Quartile } \\
\text { (8) }\end{array}$ \\
\hline & $\begin{array}{l}-0.027 \\
(0.007) \\
\end{array}$ & & $\begin{array}{l}-0.038 \\
(0.008) \\
\end{array}$ & & $\begin{array}{l}-0.031 \\
(0.017)\end{array}$ & $\begin{array}{l}-0.019 \\
(0.018)\end{array}$ & $\begin{array}{l}-0.080 \\
(0.003)\end{array}$ & $\begin{array}{l}-0.034 \\
(0.026)\end{array}$ \\
\hline cost measure & & $\begin{array}{l}-0.041 \\
(0.012)\end{array}$ & & $\begin{array}{l}-0.063 \\
(0.015)\end{array}$ & & & & \\
\hline Number of Counties & 44 & 44 & 44 & 44 & 25 & 10 & 4 & 5 \\
\hline Observations & 36527 & 36527 & 36527 & 36527 & 10239 & 8233 & 9791 & 8464 \\
\hline Mean of Dep. Var. & 0.058 & 0.058 & 0.058 & 0.058 & 0.061 & 0.061 & 0.055 & 0.054 \\
\hline Local-Area measures: & $\begin{array}{c}\text { Include } \\
\text { Floridians } \\
>100 \text { miles } \\
\text { from home } \\
\text { (9) }\end{array}$ & $\begin{array}{l}\text { Local-Area } \\
\text { Measure: } \\
\text { All Patients } \\
\text { (10) }\end{array}$ & $\begin{array}{c}\text { Local Area } \\
\text { Measure: } \\
\text { Heart } \\
\text { Emergency } \\
\text { (11) }\end{array}$ & $\begin{array}{l}\text { Local } \\
\text { Spending } \\
\text { Equal } \\
\text { Weights } \\
\text { (12) }\end{array}$ & $\begin{array}{l}\text { l-Area } \\
\text { g Quartiles } \\
\text { Weighted by } \\
\text { Sample Size } \\
\text { (13) }\end{array}$ & & & \\
\hline mean $\log ($ charges) $\mid$ mortality & $\begin{array}{l}-0.031 \\
(0.007) \\
\end{array}$ & & $\begin{array}{l}-0.023 \\
(0.008) \\
\end{array}$ & & & & & \\
\hline mean $\log$ (charges) & & $\begin{array}{l}-0.035 \\
(0.017)\end{array}$ & & & & & & \\
\hline mean $\log$ (charges) | mortality: 2nd quartile & & & & $\begin{array}{l}-0.005 \\
(0.006)\end{array}$ & $\begin{array}{l}-0.010 \\
(0.006) \\
\end{array}$ & & & \\
\hline mean $\log$ (charges) | mortality: 3rd quartile & & & & $\begin{array}{l}-0.010 \\
(0.006)\end{array}$ & $\begin{array}{l}-0.008 \\
(0.004) \\
\end{array}$ & & & \\
\hline mean $\log$ (charges) | mortality: Top quartile & & & & $\begin{array}{l}-0.019 \\
(0.006) \\
\end{array}$ & $\begin{array}{l}-0.025 \\
(0.006) \\
\end{array}$ & & & \\
\hline Number of Counties & 45 & 44 & 44 & 44 & 44 & & & \\
\hline Observations & 40701 & 36727 & 36727 & 36727 & 36727 & & & \\
\hline Mean of Dependent Variable & 0.058 & 0.058 & 0.058 & 0.058 & 0.058 & & & \\
\hline
\end{tabular}

Each cell represents a separate regression with full controls. Standard Errors are clustered at the county level. Columns (1)-(4) use probit

estimation and report marginal effects evaluated at the means of the covariates. Columns (1) and (2) use the local-area, end-of-life spending measure and are analogous to Table 1 column (8). Cost is the charge measure deflated by the hospital cost-to-charge ratio. Columns (3) and (4) report the coefficient on charges or costs in a model that included a quartic in the residuals from a first stage regression of patient charges or costs on the local-area, end-of-life measure. The number of observations is slightly smaller in the probit models that exclude 4 age and 4 homestate categories due to zero deaths in those cells. Columns (5)-(8) categorize counties by the per-diem quartiles weighted by the patient sample rather than the equal weights in Table 5. Column (9) expands the definition of visitors to include Floridians whose primary residence is greater than 100 miles from the center of the hospital's county.

Column (10) constructs the local-area measure using all emergency admissions rather than emergency admissions where the patient died in the hospital. Column (11) constructs the local-area measure using all emergency admissions where the patient died in the hospital and had a

diagnosis of acute myocardial infarction, cardiac dysrthymias, or heart failure. Columns (12) and (13) report a model that included indicators for local-area spending quartiles rather than the mean. 
Table A3: Alternative Measures of Local-Area Inputs: Heart Emergencies

\begin{tabular}{|c|c|c|c|c|}
\hline & $\begin{array}{l}\text { Mean of Measure } \\
\text { (Std. Dev.) }\end{array}$ & $\begin{array}{l}\text { Correlation with Local } \\
\log \text { (charges)|mortality }\end{array}$ & $\begin{array}{l}\text { Coefficient (s.e.) from } \\
\text { model of Mortality }\end{array}$ & Obs. \\
\hline & $(1)$ & $(2)$ & (3) & $(4)$ \\
\hline \multicolumn{5}{|l|}{ Local Area Charge Measures | Mortality } \\
\hline \multirow[t]{2}{*}{$\log$ (room charges) } & 7.20 & 0.28 & 0.004 & 36727 \\
\hline & 0.23 & & $(0.011)$ & \\
\hline \multirow[t]{2}{*}{$\log$ (nursery charges) } & 7.47 & -0.70 & 0.004 & 8844 \\
\hline & 0.67 & & $(0.001)$ & \\
\hline \multirow[t]{2}{*}{$\log$ (intensive care unit charges) } & 7.97 & 0.68 & -0.019 & 36727 \\
\hline & 0.24 & & $(0.008)$ & \\
\hline \multirow[t]{2}{*}{$\log ($ coronary care unity charges) } & 7.92 & 0.47 & -0.007 & 34994 \\
\hline & 0.29 & & $(0.010)$ & \\
\hline \multirow[t]{2}{*}{$\log ($ pharmacy charges) } & 7.97 & 0.83 & -0.015 & 36727 \\
\hline & 0.33 & & $(0.007)$ & \\
\hline \multirow[t]{2}{*}{ log(medical and surgical supply charges) } & 7.41 & 0.71 & -0.005 & 36727 \\
\hline & 0.28 & & $(0.009)$ & \\
\hline \multirow[t]{2}{*}{ log(oncology charges) } & 4.15 & 0.86 & 0.005 & 3662 \\
\hline & 1.19 & & $(0.001)$ & \\
\hline \multirow[t]{2}{*}{ log(laboratory charges) } & 8.12 & 0.85 & -0.019 & 36727 \\
\hline & 0.32 & & $(0.006)$ & \\
\hline \multirow[t]{2}{*}{ log(pathology laboratory charges) } & 5.45 & 0.53 & -0.011 & 36589 \\
\hline & 0.44 & & $(0.004)$ & \\
\hline \multirow[t]{2}{*}{ log(diagnostic radiology charges) } & 6.63 & 0.17 & -0.008 & 23768 \\
\hline & 0.92 & & $(0.002)$ & \\
\hline \multirow[t]{2}{*}{$\log$ (therapeutic radiology charges) } & 7.09 & 0.047 & 0.007 & 36622 \\
\hline & 0.22 & & $(0.014)$ & \\
\hline \multirow[t]{2}{*}{$\log$ (nuclear medicine charges) } & 7.44 & 0.60 & -0.033 & 36727 \\
\hline & 0.19 & & $(0.010)$ & \\
\hline \multirow[t]{2}{*}{$\log$ (ct scan charges) } & 6.83 & 0.089 & 0.004 & 36649 \\
\hline & 0.65 & & $(0.002)$ & \\
\hline \multirow[t]{2}{*}{ log(operating room charges) } & 6.82 & 0.27 & -0.002 & 36617 \\
\hline & 0.43 & & $(0.004)$ & \\
\hline \multirow[t]{2}{*}{$\log$ (anesthesia charges) } & 6.76 & 0.83 & -0.022 & 36727 \\
\hline & 0.35 & & $(0.005)$ & \\
\hline \multirow[t]{2}{*}{ log(respiratory services charges) } & 6.05 & 0.65 & -0.020 & 36683 \\
\hline & 0.31 & & $(0.013)$ & \\
\hline \multirow[t]{2}{*}{$\log$ (physical therapy charges) } & 5.80 & 0.43 & -0.002 & 35380 \\
\hline & 0.40 & & $(0.008)$ & \\
\hline \multirow[t]{2}{*}{$\log$ (occupational therapy charges) } & 6.35 & 0.40 & -0.022 & 36727 \\
\hline & 0.19 & & $(0.011)$ & \\
\hline \multirow[t]{2}{*}{ log(emergency room charges) } & 7.26 & 0.29 & 0.008 & 36727 \\
\hline & 0.26 & & $(0.008)$ & \\
\hline \multirow[t]{2}{*}{$\log$ (cardiology charges) } & 7.66 & 0.47 & 0.007 & 36727 \\
\hline & 0.35 & & $(0.005)$ & \\
\hline $\log$ (magnetic resonance imaging charges) & 9.73 & 0.96 & -0.028 & 36727 \\
\hline & 0.23 & & $(0.007)$ & \\
\hline log(recovery room charges) & 7.68 & -0.032 & -0.002 & 35702 \\
\hline & 0.29 & & $(0.008)$ & \\
\hline log(labor room charges) & 6.31 & 0.17 & -0.010 & 36547 \\
\hline & 0.37 & & $(0.005)$ & \\
\hline log(other charges) & 6.40 & 0.008 & -0.021 & 5733 \\
\hline & 1.23 & & $(0.003)$ & \\
\hline
\end{tabular}

Each row represents a separate regression with full controls. Standard Errors are clustered at the county level. The number of observations varies as small counties with no charges within the given category are not used. 